\title{
INVESTIGATION OF DYNAMIC CABLE-DECK INTERACTION IN A PHYSICAL MODEL OF A CABLE-STAYED BRIDGE PART II: SEISMIC RESPONSE
}

\author{
E. CAETANO and A. CUNHA \\ Faculty of Engineering of University of Porto, Rua dos Bragas, 4099 Porto Codex, Portugal \\ C. A. TAYLOR \\ Earthquake Engineering Research Centre, University of Bristol \\ Queen's Building, University Walk, Bristol BS8 1TR, U.K.
}

\begin{abstract}
SUMMARY
The present paper describes an investigation of the effect of dynamic cable interaction with the deck and towers in the seismic response of a cable-stayed bridge. This study involved shaking table tests performed on a physical model of Jindo bridge, in order to validate two alternative numerical models, which differ in terms of consideration of coupled cable/deck and towers modes. The response to artificial accelerograms was calculated and correlated with measured data. Additional numerical simulations are presented in order to clarify the role that cables play in the attenuation or amplification of the structural response. It was found that the cable interference with global oscillations may cause a decrease of the bridge response. However, this "system damping" may not develop in the case where a narrow band excitation is applied, causing large amplitude of vibrations of some cables, with significant nonlinearity, and inducing higher order modes.
\end{abstract}

KEY WORDS: Cable-stayed bridges; physical models; seismic response; shaking table; cable dynamics.

\section{INTRODUCTION}

Cables are very efficient structural elements widely used in many large span bridges, such as cable-stayed or suspension bridges. Since they are light, very flexible and lightly damped, cable 
structures can always face important dynamic problems under different types of loads, e.g. wind, earthquake or traffic loads, which requires appropriate modelling, in order correctly to predict and control the structural response.

Evidence of significant stay cable oscillations, sometimes conjugated with simultaneous vibrations of the deck, has been made by long-term monitoring of several modern bridges. Although several reasons have been adduced to justify that behaviour, such as the direct turbulent wind excitation, eventually conjugated with rain, vortex shedding phenomena and motion of the cable supports, the mechanism behind these oscillations is not yet fully explained.

However, it is sometimes suggested that cable vibrations can play a favourable role in terms of the dynamic behaviour of cable-stayed bridges, under wind or earthquake excitations, contributing to the development of an additional damping ("system damping") in the structural response. This concept was first introduced by Leonhardt et al. ${ }^{1}$, who attributed this peculiar behaviour of cable-stayed bridges both to the non-linear behaviour of the cables, associated with the sag effect, and to the interference of cable oscillations at different natural frequencies. More recently other researchers have newly defined a governing cause of system damping using the concept of internal resonance ${ }^{2}$.

The most common practice of numerical analysis of cable-stayed bridges consists in the development of a finite element model where the cables are represented by single truss elements with equivalent Young modulus ${ }^{3}$. Such a procedure precludes lateral cable vibrations, thus leading to a separate treatment of local and global vibrations ${ }^{4}$, the first referring to transverse oscillations of a cable between fixed supports, while the second corresponds to the motion of the girder, pylon and cables as an assemblage, the cables behaving as elastic tendons. The interaction between local and global vibrations has been investigated by several researchers, such as Maeda et al. ${ }^{2}$, Causevic and Sreckovic ${ }^{5}$, Kovacs ${ }^{6}$, Abdel-Ghaffar and Khalifa ${ }^{7}$, Fujino et al. ${ }^{4}$, and Tuladhar and Brotton ${ }^{8}$. Causevic and Sreckovic modelled the cables as assemblages of linear springs and masses, and stressed the importance of the nonlinearity of cable behaviour that results from the closeness between a cable natural frequency and a natural frequency of the global structure. Abdel-Ghaffar and Khalifa modelled the cables using a multiple link method previously used by Baron and Lien ${ }^{9}$, Maeda et al. ${ }^{2}$, Yiu and Brotton ${ }^{10}$ and Tuladhar and Brot- 
ton $^{8}$, and showed that cable vibrations affect the mode shapes of the deck/towers system and the corresponding participation factors. The inadequacy of using single truss elements to model the cables and the necessity of considering a convenient discretization of the cables into several finite elements was also stressed by Tuladhar et al. ${ }^{11}$, who concluded that the interaction between cable vibrations and deck vibrations can have a significant influence on the seismic response of the bridge, especially when the first natural frequencies of cables overlap with the first few frequencies of the bridge.

\section{OBJECTIVES OF THE STUDY}

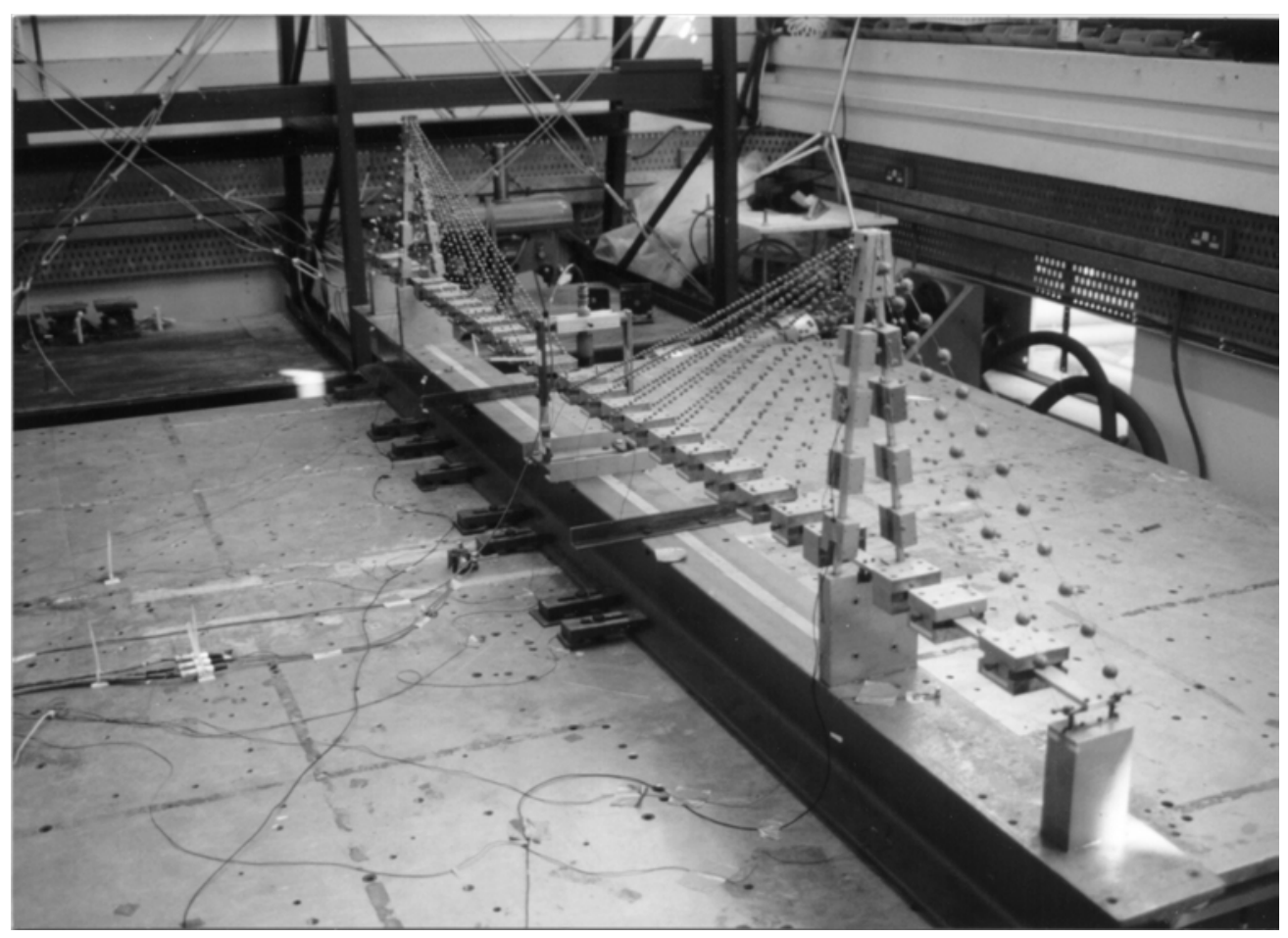

Figure 1. Physical model of Jindo Bridge on the shaking table

To complement the above mentioned numerical investigations, the authors conducted an experimental study on an existing physical model of a cable-stayed bridge ${ }^{12}$, the Jindo bridge (in South Korea), which was modified for the purpose of studying the dynamic behaviour of the cables (Figure 1). The description of this bridge and of a series of modal analysis tests performed on the model is presented in a companion paper ${ }^{13}$. The study confirmed the existence of interaction between the cables and the deck/towers, which in this case is characterised by the 
appearance of several modes of vibration with very close natural frequencies and with similar mode shape configurations of the deck and towers, but involving different movements of the cables. The appearance of these new mode shapes proved to be conditioned by the closeness between a natural frequency of the global structure and the natural frequencies of some cables.

In the present paper, the authors attempt to evaluate the importance of the dynamic cable/deck interaction in terms of the response to seismic excitations. The study involved an experimental component that consisted of a series of shaking table tests, using different types of artificial accelerograms as input. The measured response was then used to validate finite element models previously developed, in which the cables were idealised either as simple truss elements, or as sets of several truss elements (multiple link method).

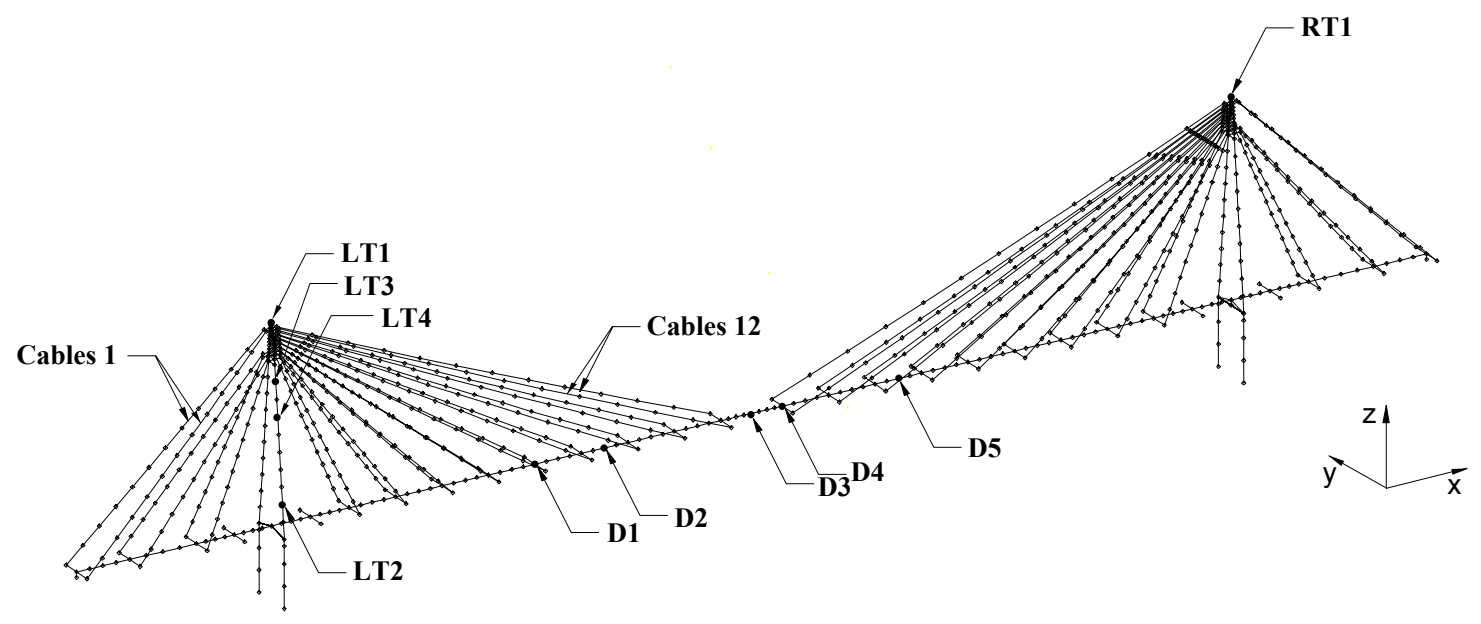

Figure 2. Structural discretization used in the MECS model

The analysis and comparison of the experimental and calculated responses obtained under each of the two finite element models developed, OECS (One-Element Cable System) and MECS (Multi-Element Cable System), showed, as will be demonstrated later, the following main aspects: (i) a good correlation between the experimental and calculated responses predicted by both numerical models; (ii) some slight differences between the OECS and MECS responses, which did not reveal however any significant "system damping" effect for the type of excitation considered.

Two different numerical simulations were subsequently performed, in order to enhance and better understand this situation. The first consisted of modifying the natural frequency of the 
fundamental mode of vibration to the range of the first frequency of the cables. The second corresponded to the analysis of the response of the Jindo model to a severe high amplitude base excitation defined in a narrow frequency range, containing both a natural frequency of the structure, and the 1st frequencies of some cables. It was found that the cable interference with global oscillations may cause a significant decrease of the bridge response (with regard to standard OECS analysis, where the local behaviour of the cable is not modelled). However, this "system damping" may not develop in the case where a narrow band excitation is applied. In this case, the large amplitude of vibration of some cables may cause significant nonlinearity and induce higher order modes, thus causing an increase of the response.

\section{MODAL PROPERTIES OF THE PHYSICAL MODEL OF JINDO BRIDGE}

According to the results already presented in the companion paper ${ }^{13}$, two 3-D finite element models were developed and appropriately validated on the basis of the experimental data: the OECS (One-Element Cable System) and the MECS (Multi-Element Cable System). The two models idealise the structure as an assemblage of beam and truss elements and differ only in the number of truss elements used to represent the stay cables. The OECS employs a simple truss element to describe each stay cable, while the MECS idealizes each cable as a set of several truss elements.

The calculation of natural frequencies and mode shapes presented in ${ }^{13}$ was based on a tangent stiffness matrix, obtained at the end of a geometric non-linear static analysis of the structure under permanent load, and on a lumped mass matrix. A subspace iteration algorithm, integrated in a structural analysis software, SOLVIA ${ }^{14}$, was used to extract the first 20 modes associated with the OECS model, in the range 0-46 Hz, and the first 150 modes related with the MECS model, lying in the range $0-21.3 \mathrm{~Hz}$.

A plot of the calculated frequencies obtained from the MECS analysis against the order of the mode is presented in Figure 3. The frequencies associated with the OECS analysis are also represented in this figure, in correspondence with the mode of closer characteristics ob- 
tained in the MECS analysis (VSYM and VASM- vertical symmetric and anti-symmetric bending modes; TSYM and TASM- transversal symmetric and anti-symmetric bending modes). It is clear from the figure that the numerous modes of vibration that resulted from the modelling of local cable behaviour are separated by flat regions, which can generally be associated with a common configuration of the deck and towers. These sets of modes involve different movements of the cables, with a varying intensity level (relative to the girder/towers movement), and occur at an almost identical natural frequency.

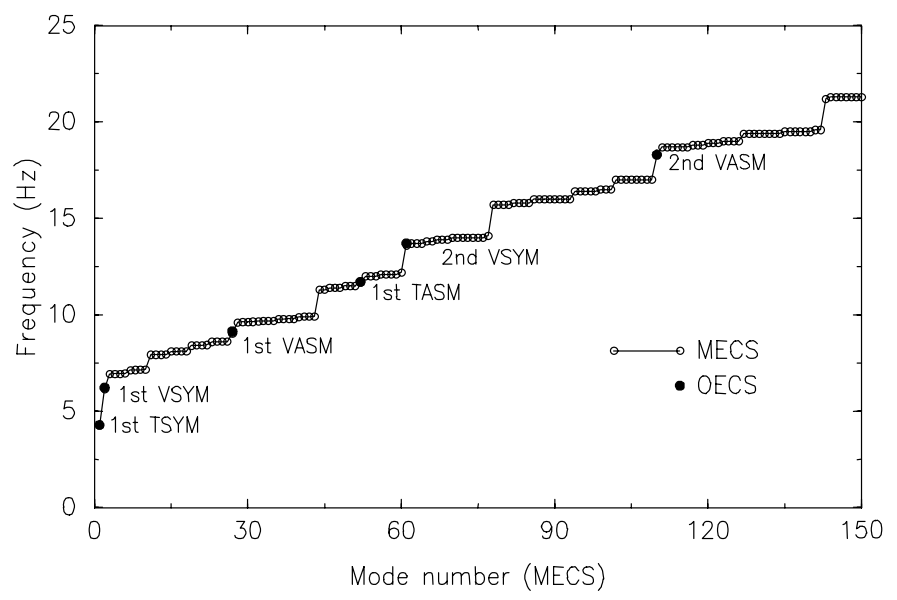

Figure 3. OECS vs MECS natural frequencies

Figure 4 presents the participation factors calculated for both the OECS and MECS models. It is evident, from the analysis of these figures and of the mode shape configurations, that: (i) the structural response along the vertical (Z) and transversal (Y) directions is clearly dominated by one mode of vibration (the $1^{\text {st }}$ VSYM and the $1^{\text {st }}$ TSYM modes, respectively); (ii) the structural response along the longitudinal (X) direction is strongly conditioned by two vertical anti-symmetric modes (the $1^{\text {st }}$ VASM and the $2^{\text {nd }}$ VASM). Another aspect to refer to is that although the highest participation factors associated with the OECS modes are in some cases slightly higher than the corresponding to modes obtained from the MECS analysis, the participation factors associated with the new mode shapes may have some significance for the response evaluation. This fact justifies the importance of the present investigation. 

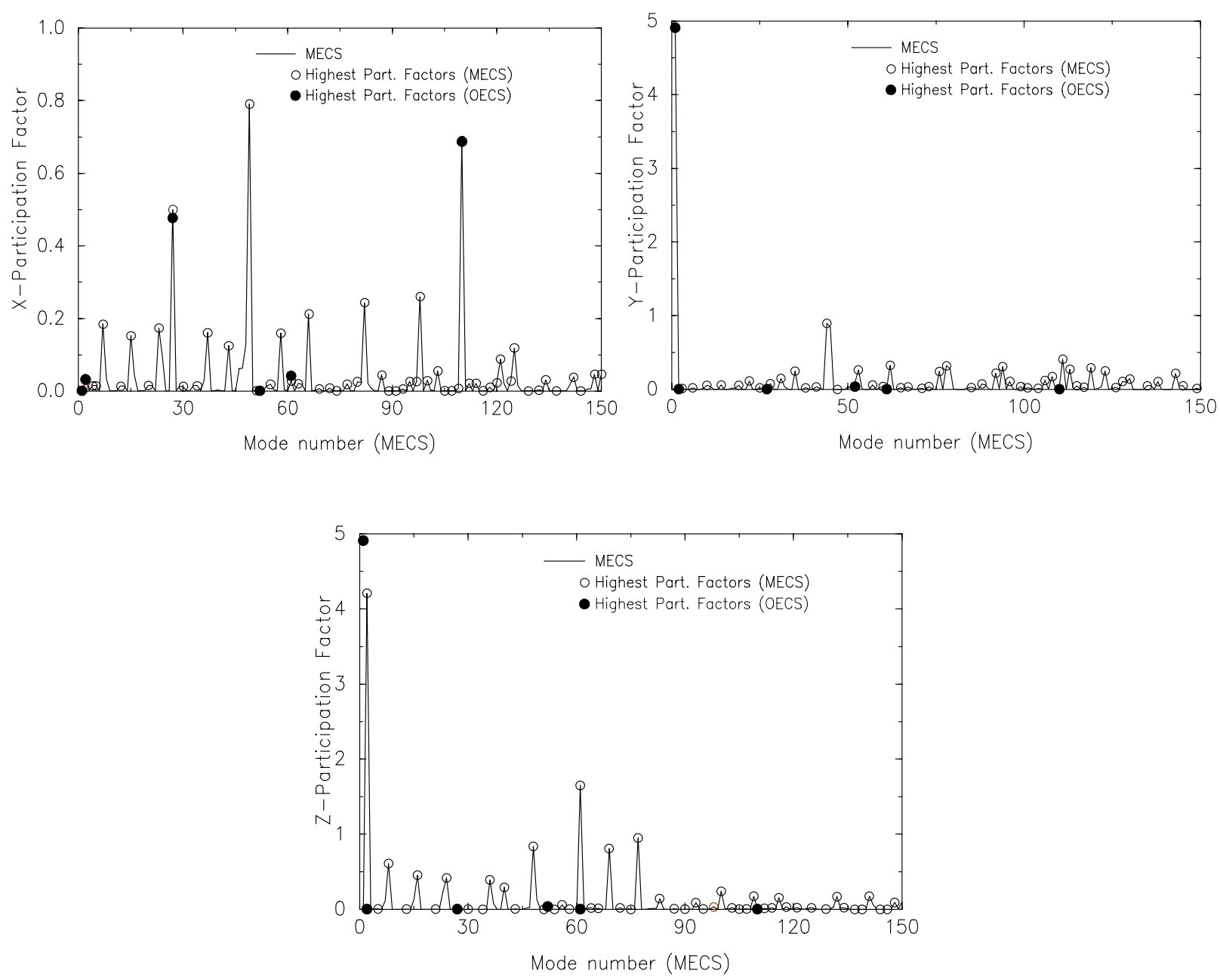

Figure 4. Participation factors associated with models OECS and MECS

\section{SEISMIC TESTS ON THE SHAKING TABLE}

The shaking table tests of the Jindo bridge physical model were conducted at the Earthquake Engineering Research Centre of the University of Bristol. Three different ground acceleration time histories (with about $30 \mathrm{~s}$ duration for the prototype) were generated and scaled (the scale factor for time measurements is $S_{t}=\sqrt{150}$, according to Caetano et al. ${ }^{13}$ ) based on three different target response spectra. The definition of these response spectra attempted, in the first instance (records RRS1), to excite predominantly the fundamental modes of the cables, whereas, in a second situation, the objective was to excite essentially the first mode shape of the structure. The non-stationarity of the seismic action was introduced in terms of amplitude by the application of a trapezoidal time modulation function, simulating the usual three phases of a common 
accelerogram. A third time history was generated introducing also a non-stationarity in terms of the frequency content.
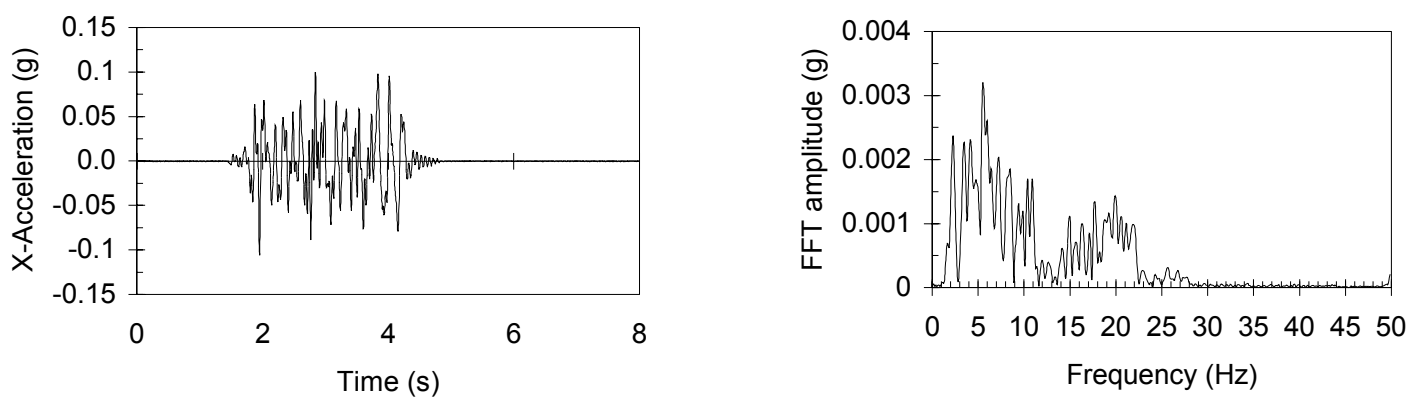

Figure 5. Example of an artificial record of seismic action. Acceleration time history along the longitudinal direction $\mathrm{X}$ and Fourier spectrum

Graphical representations of an acceleration time series measured on the shaking table platform and of the corresponding single sided Fourier spectrum are presented in Figure 5. These correspond to a component of the record RRS1 along the longitudinal direction X (i.e. along the axis of the deck) with about $10 \% \mathrm{~g}$ peak value.
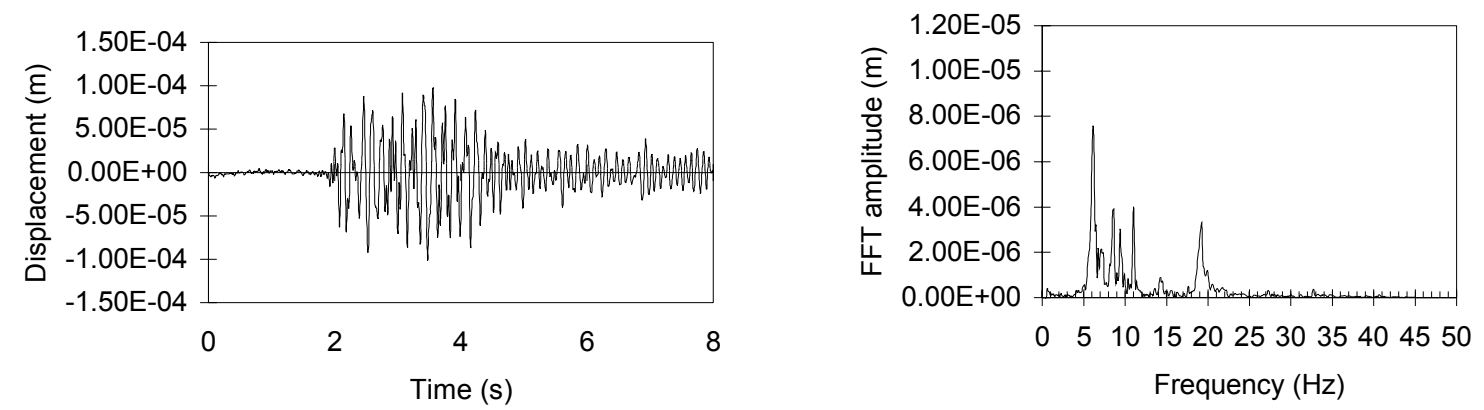

(a)
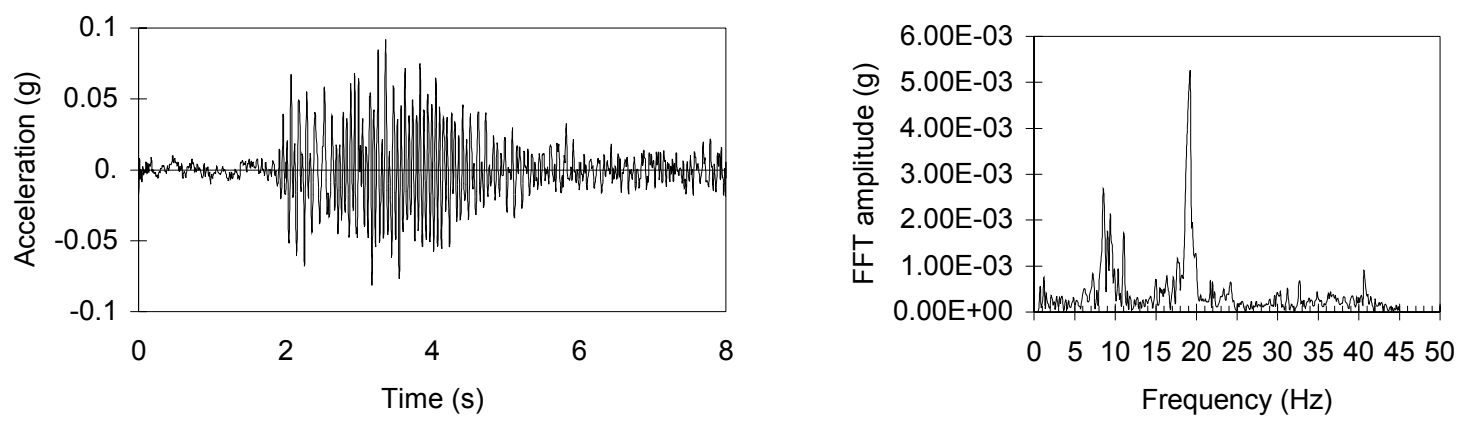

(b)

Figure 6. Examples of measured responses for input RRS1, 10\%g (X):

(a) Node D4-Z; (b) Node D5-Z 
The response was measured for three input directions, $\mathrm{X}$ (longitudinal), Y (transversal) and $\mathrm{Z}$ (vertical), and for the combinations $\mathrm{XZ}$ and $\mathrm{XYZ}$, with about 5\%g and $10 \% \mathrm{~g}$ peak values along the two horizontal directions, and about 3\%g and $6 \% \mathrm{~g}$ in the vertical direction. A total of 13 small piezoelectric accelerometers and 1 non-contact displacement transducer were used to obtain simultaneous measurements along the bridge. Figures 6 and 7 present a few examples of the measured response at some important locations (see Figure 2).
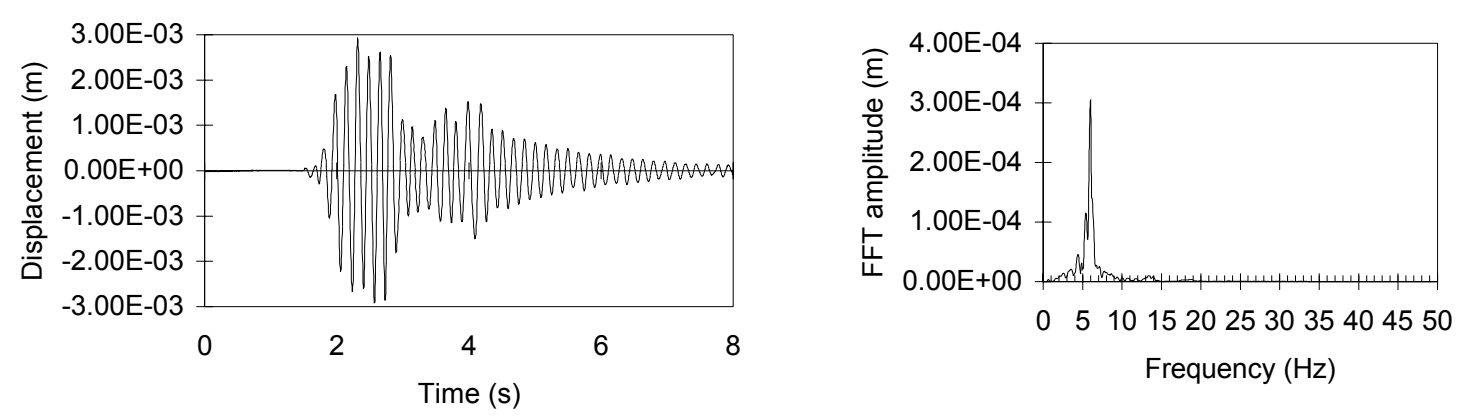

(a)
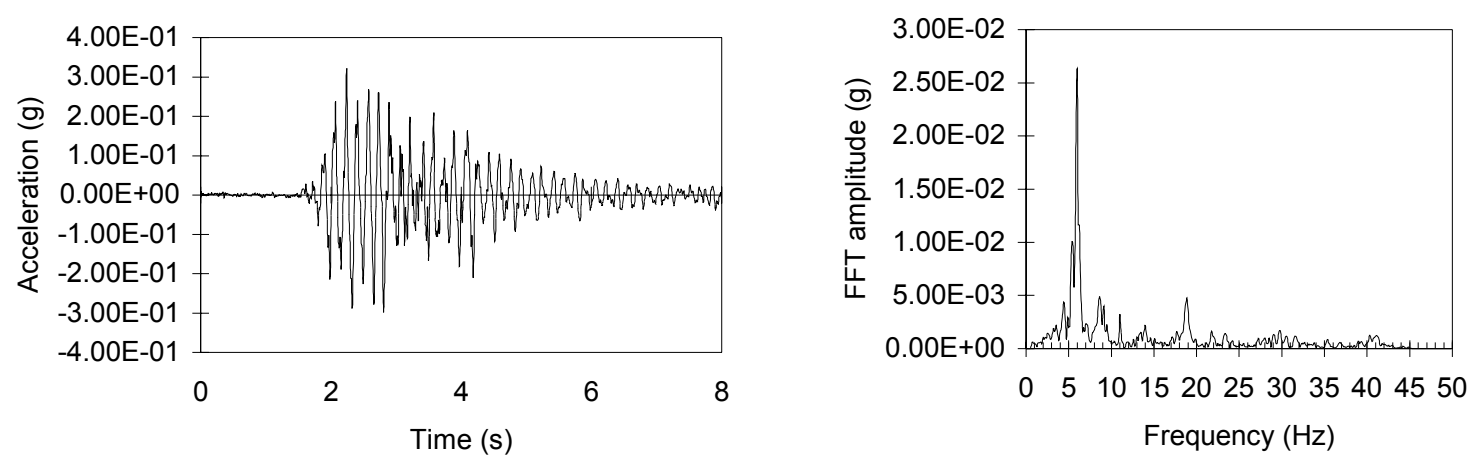

(b)
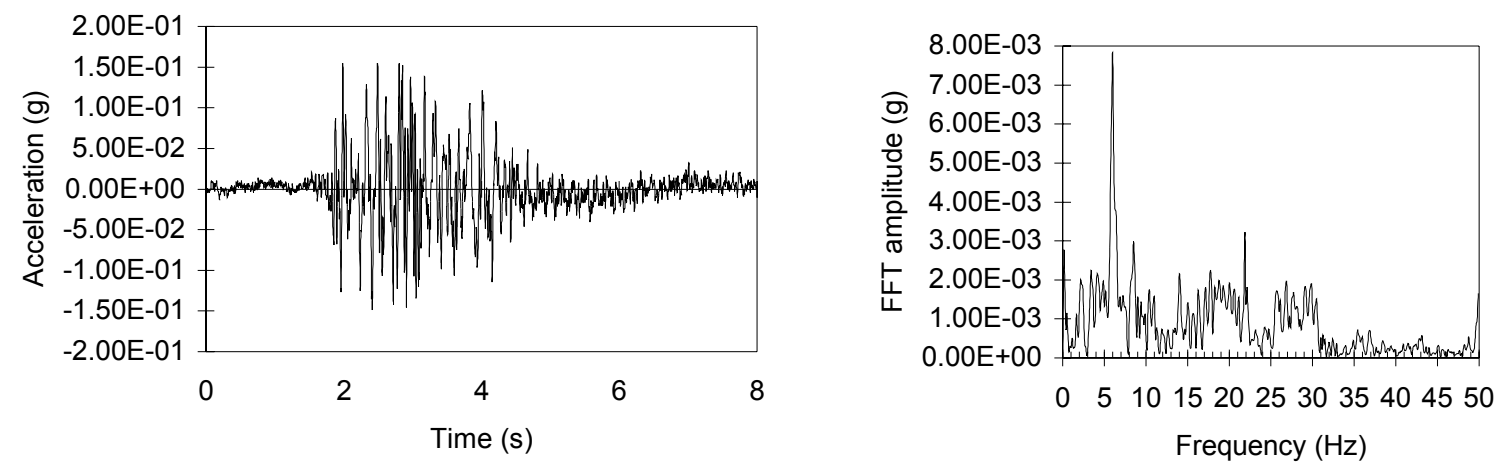

(c)

Figure 7. Examples of measured responses for input RRS1, 10\%g $(X), 6 \% g(Z)$ : (a) Node D4-Z; (b) Node D5-Z; (c) Node LT1-X 


\section{ANALYSIS OF THE SEISMIC RESPONSE}

Using the accelerograms measured on the seismic platform, the response of both OECS and MECS models to different combinations of time series from the input records has been evaluated, based on a direct integration algorithm (Newmark method) and on a geometric non-linear dynamic analysis. Table I summarises some measured and calculated absolute peak values on some of the most significant nodes of the structure (mid-span, node D3-Z; attachment of longest cable, node D4-Z; third of span, node D5-Z; top of left tower, node LT1-X), for an input defined as a $\mathrm{XZ}$ combination $(10 \% \mathrm{~g} \mathrm{X}, 6 \% \mathrm{~g} \mathrm{Z})$ of time series from record RRS 1 .

Table I. Measured and calculated peak response for input RRS1: 10\%g (X), 6\%g (Z)

\begin{tabular}{cccc}
\hline Node component & Experimental & OECS & MECS \\
\hline D4-Z, Displ. (m) & $-0.0029 / 0.0029$ & $-0.0026 / 0.0025$ & $-0.0025 / 0.0026$ \\
\hline D3-Z, Accel.(m/s $)$ & $-6.6 / 6.5$ & $-4.8 / 4.1$ & $-5.7 / 4.4$ \\
D4-Z, Accel.(m/s $\left./ \mathrm{s}^{2}\right)$ & $-4.2 / 4.6$ & $-4.5 / 4.0$ & $-5.3 / 4.3$ \\
D5-Z, Accel.(m/ $\left.\mathrm{s}^{2}\right)$ & $-2.9 / 3.2$ & $-3.1 / 3.0$ & $-3.1 / 3.7$ \\
LT1-X, Accel.(m/s $\left.\mathrm{s}^{2}\right)$ & $-1.5 / 1.5$ & $-1.2 / 1.2$ & $-1.0 / 0.9$ \\
\hline
\end{tabular}

Due to the difficulty of accurately reproducing the real damping characteristics of the physical model, damping was numerically modelled by means of a mass proportional damping matrix, which was formed specifying a modal damping factor $\xi_{1}=1.0 \%$ for the first vertical bending mode of vibration $\left(f_{1}=6.20 \mathrm{~Hz}\right)$. This value resulted from the analysis of the measured response. It is important to note that sensitivity studies developed to fix the value of this damping coefficient showed that it has a strong influence both on the peak values of the response that occur in a first part of the records, particularly in terms of accelerations, and on the corresponding decay phase. So the value adopted represents a compromise in order to achieve a relatively good global agreement between the experimental and numerical responses, and not exclusively in terms of local response peak values.

Figure 8 presents a comparison between experimental and calculated responses for one specific node of the structure, D4-Z. Figure 9 presents the Fourier spectra associated with those experimental and calculated responses. The global peak response of the bridge in terms of 
maxima displacements, accelerations, bending moments and axial forces along the deck, the cables and one of the towers is depicted in Figures 10 to 12. Note that only the dynamic component of the response is analysed here.

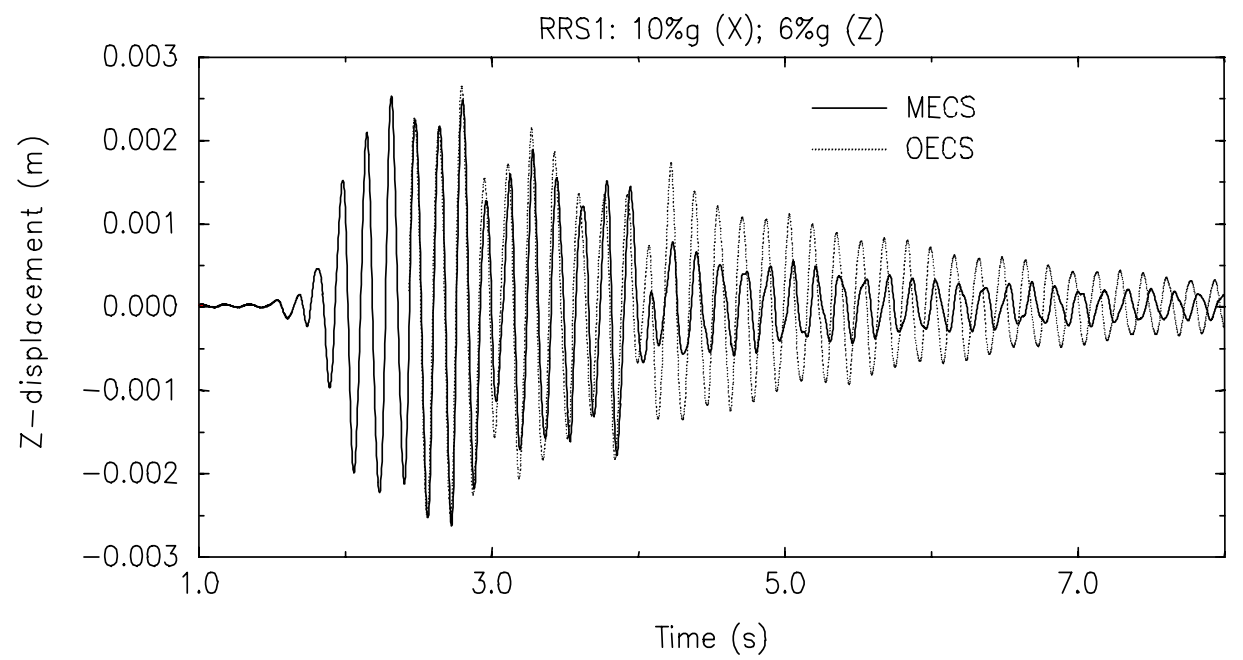

(a)

(b)

Figure 8. Displacement at node D4-Z (a) calculated, OECS vs MECS, structural damping included; (b) experimental vs calculated response, MECS, structural damping included 


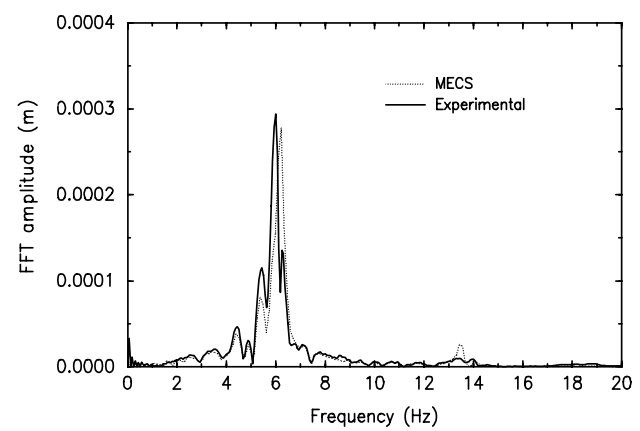

(a)

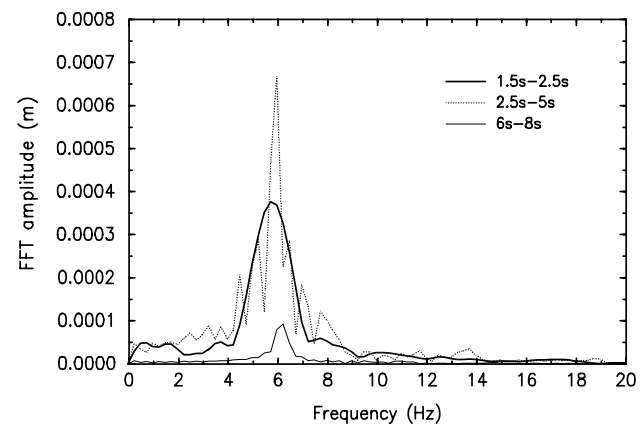

(c)

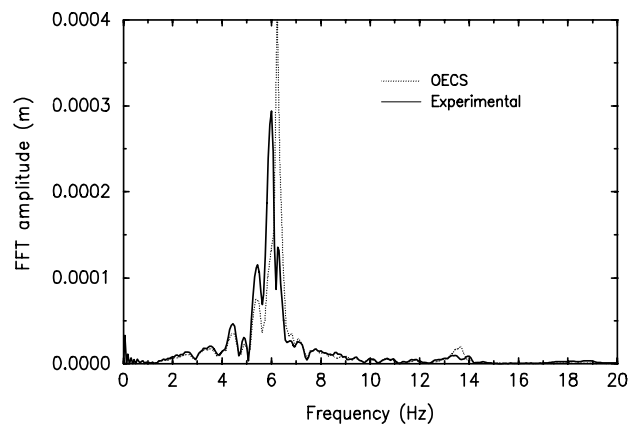

(b)

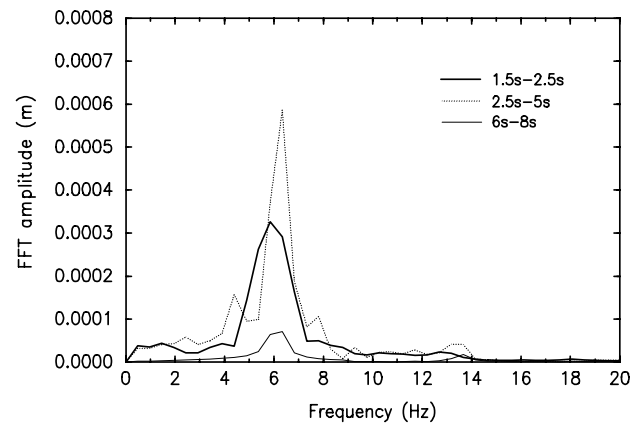

(d)

Figure 9. Fourier spectra at node D4-Z: (a) experimental vs MECS, structural damping included; (b) experimental vs OECS, structural damping included; (c) experimental, segment analysis; (d) MECS, segment analysis, structural damping included

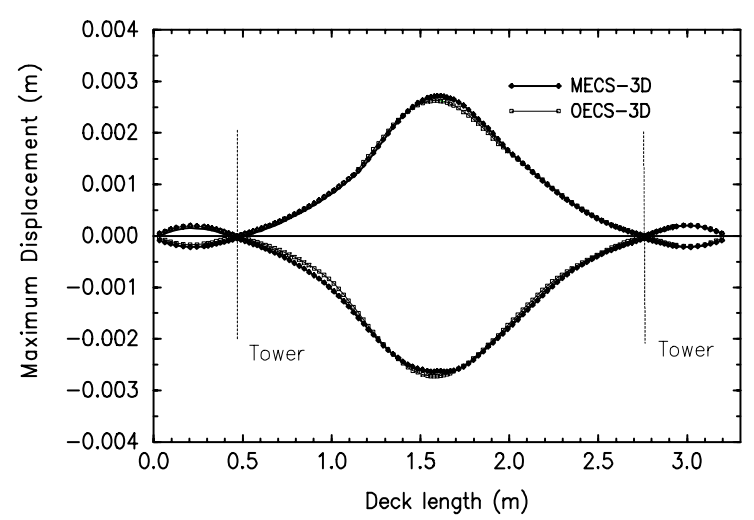

(a)

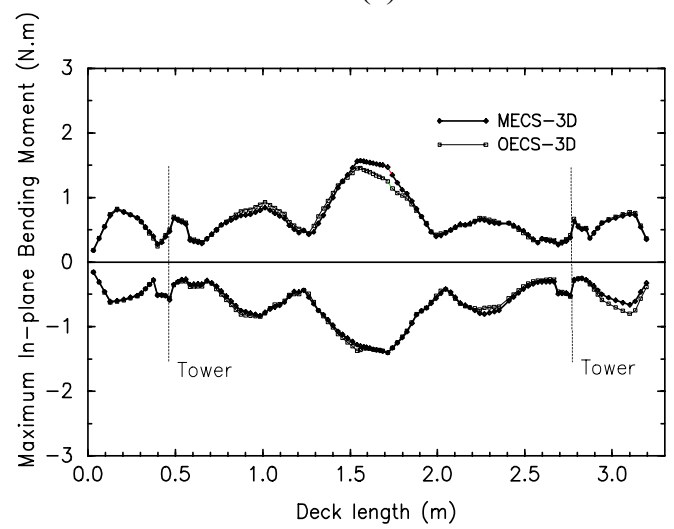

(c)

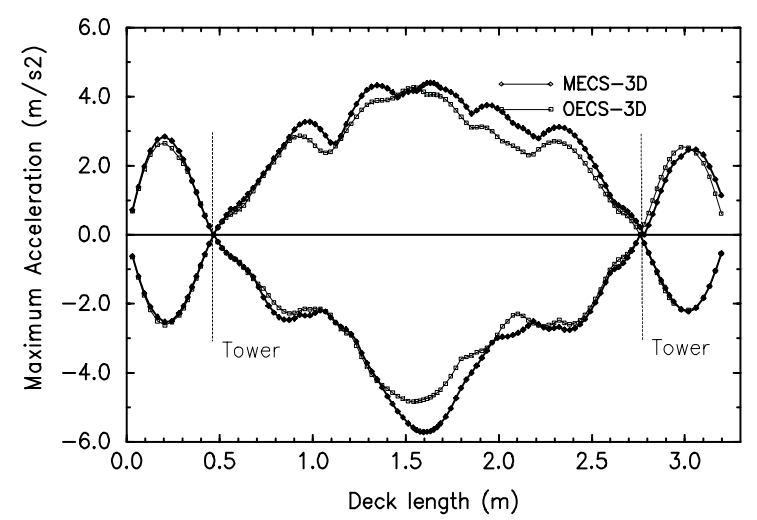

(b)

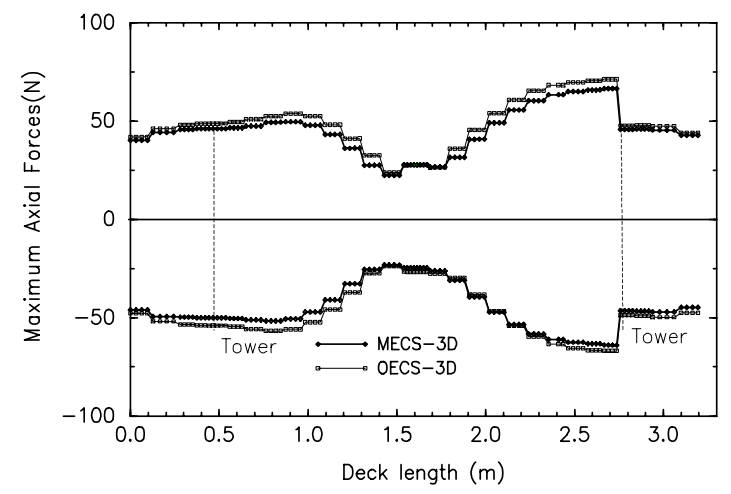

(d)

Figure 10. Peak values of the calculated response along the girder, OECS vs MECS analysis: displacements, accelerations, bending moments and axial forces 

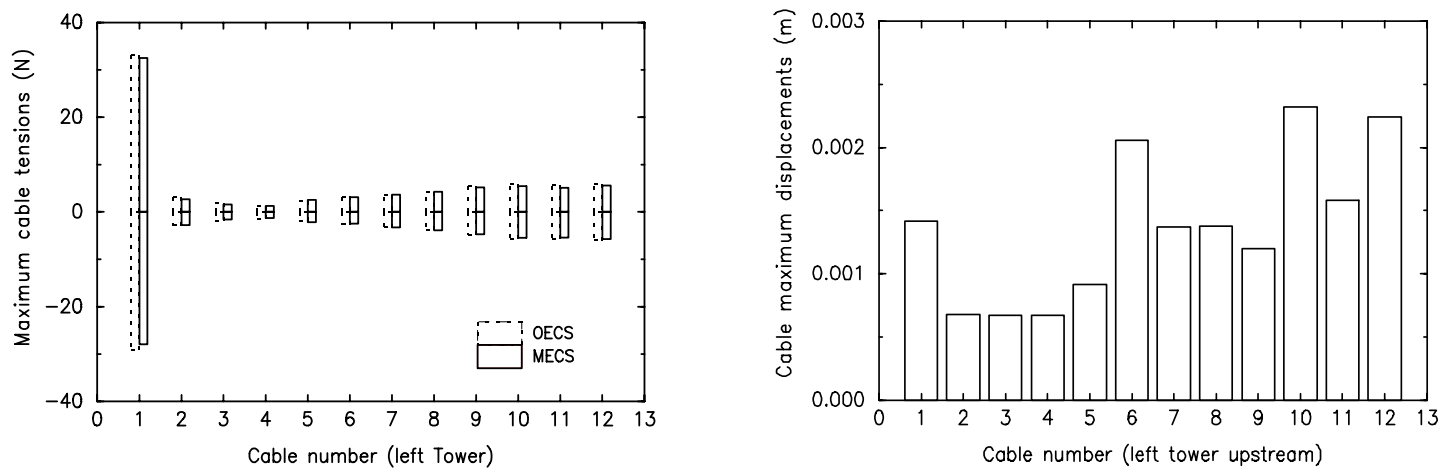

Figure 11. Peak values of cable response: (a) tension, OECS vs MECS analysis; (b) peak displacements at the midpoint of cables
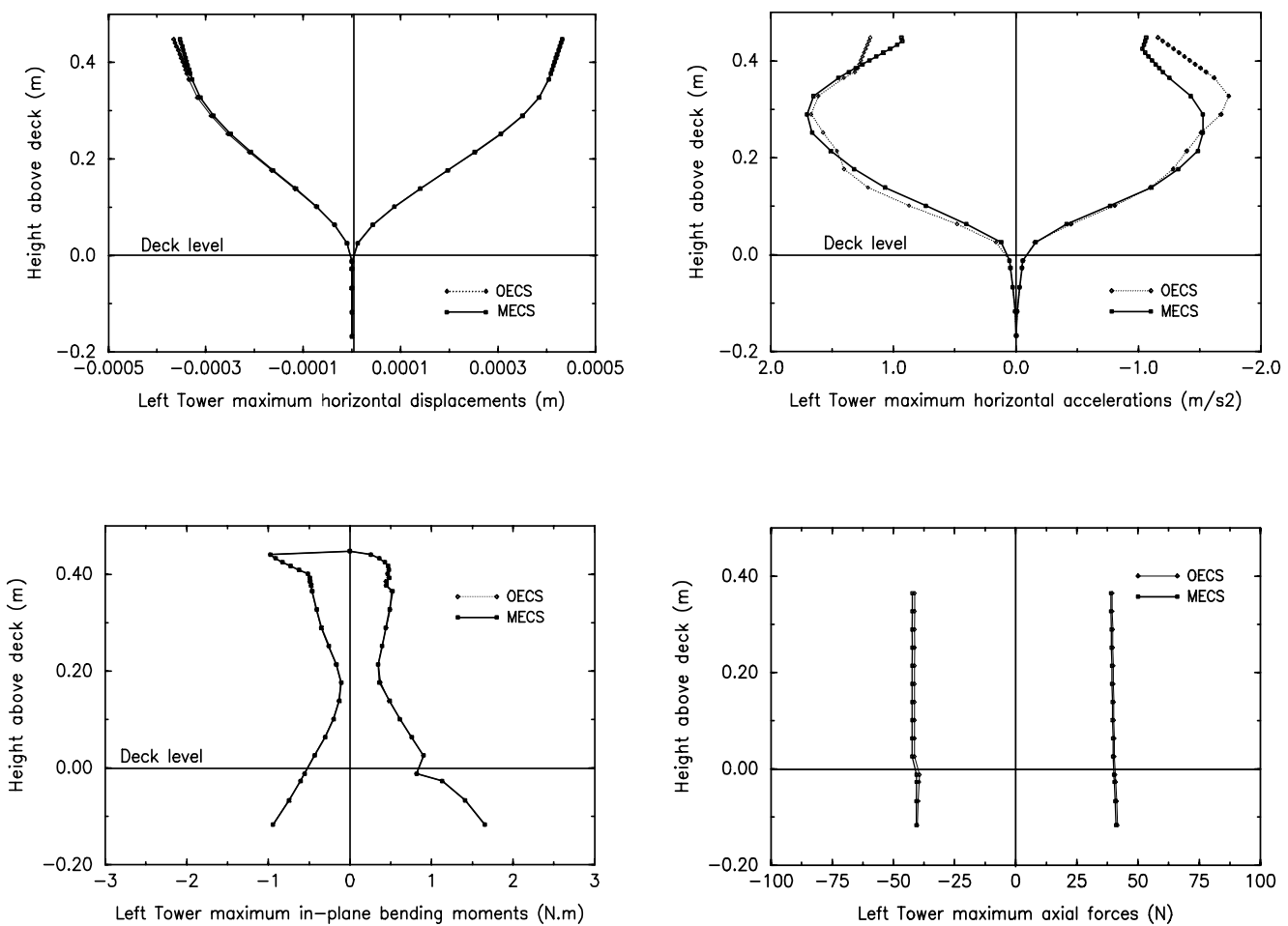

Figure 12. Peak values of the calculated response along one tower, OECS vs MECS analysis: displacements, accelerations, bending moments and axial forces

Inspection of Table I and of Figures 8 to 12 suggest in particular the following comments:

- The MECS model leads to a slight modification of the response. The variation of the peak response is relatively small, as can be observed in Figures 10 to 12 and in Table II, which shows some values of the most significant changes in the negative and positive peak response that resulted from a MECS analsyis, with regard to a standard OECS analysis. 
Table II. Change of peak response, MECS vs OECS analysis

\begin{tabular}{lcccc}
\hline & \multicolumn{4}{c}{ Change of peak response $(\operatorname{MECS} / \operatorname{OECS})(\%)$} \\
\cline { 2 - 5 } Type of response & Deck & Node no. & Towers & Node no. \\
\hline Displacement & $105.9 / 115.7$ & $\mathrm{D} 4-Z$ & $96.4 / 99.8$ & LT1-X \\
Acceleration & $122.1 / 106.2$ & $\mathrm{D} 4-Z$ & $91.4 / 78.6$ & LT4-X \\
Bending moment & $100.0 / 115.4$ & $\mathrm{D} 4$ & $98.9 / 100.4$ & LT3 \\
Axial force & $103.4 / 89.5$ & $\mathrm{D} 5$ & $102.4 / 98.6$ & LT3 \\
\hline
\end{tabular}

- It is also possible to observe three distinct periods in the response analysis. During a first period of about $1 \mathrm{~s}(12 \mathrm{~s}$ in the prototype), i.e., from $1.5 \mathrm{~s}$ to $2.5 \mathrm{~s}$, the response obtained on the basis of the OECS model is similar to the corresponding response obtained using the MECS model. Then, the MECS response starts to deviate from the OECS response, suffering a significant reduction during the next 2 seconds, after which the relative difference maintains approximately constant. Figure 8 shows these phases for the vertical displacement at node D4. It can be observed that the MECS analysis leads to a displacement decrease at node D4-Z, of about $50 \%$.

- A comparison with the experimental data shows that, during the first $1 \mathrm{~s}$ of excitation (1.5s$2.5 \mathrm{~s}$ ), both the OECS and MECS signals are slightly lower than the measured response. Figure 8 (b) shows a second period, from about $2.5 \mathrm{~s}$ to about $5 \mathrm{~s}$, where a gradual phase deviation between the experimental and the numerical response occurs. This corresponds, in practice, to changes of the fundamental frequency of the measured response. The deviations in relation to the numerical response start to reduce again in the final part of the records. The observation of Figure 9(c) indicates that, during this second part of the motion, the fundamental frequency of the measured response is lower than the corresponding frequency at the final part of the record. Neither the OECS nor the MECS analyses (Figure 9(d)) were able to reproduce this behaviour, probably due to the practical difficulty of accurate numerical modelling of local particularities and slight imperfections of the physical model. 
Figures 8 and 9 show that the structural response is strongly dominated by the first vertical mode shape, due to the important frequency content of the input excitation used in this analysis, in the vicinity of the corresponding natural frequency. This mode does not involve a significant cable interaction, and so the differences obtained between responses calculated on the basis of the OECS and MECS models are relatively small. In fact, the analysis points to the existence of a certain amount of vibration damping provided by the stay cables, which leads to a decrease of the response only a few seconds after the beginning of the excitation. However this damping is rather small, as the amplitude of the cable movements is not induced to a great extent. Moreover, as this damping does not occur immediately after the structure starts vibrating, the effect on the reduction of peak response to seismic action is not significant.

\section{NUMERICAL INVESTIGATION OF DYNAMIC CABLE INTERACTION WITH DECK AND TOWERS}

The seismic tests and numerical analysis described above evidenced the following particular aspects:

- The frequency of the fundamental vertical bending mode of vibration of the bridge $(6.21 \mathrm{~Hz})$ lies outside the range of the first frequency of the cables $(6.81-18.92 \mathrm{~Hz}$, according to Irvine theory, see Table III in the companion paper $^{13}$ ). This fact, accompanied by the significant $\mathrm{z}$ participation factor associated to this mode, may have contributed to an attenuation of the damping effect induced in the response by the stay cables;

- Some of the cables (cables 6, 10 and 12, with fundamental frequencies of $13.11 \mathrm{~Hz}, 9.39 \mathrm{~Hz}$ and $6.81 \mathrm{~Hz}$, respectively) experienced higher levels of vibration than the others. Considering that the first three natural frequencies of the structure, obtained on the basis of the OECS analysis, associated with vertical bending modes, are $6.21 \mathrm{~Hz}, 9.12 \mathrm{~Hz}$ and $13.74 \mathrm{~Hz}$, it seems clear that major cable effects occur when a global natural frequency lies in the range of the first natural frequencies of some cables. 
In order better to understand these points, and taking into account the existence of a significant number of stay cables with fundamental frequencies close to the frequency of the first vertical anti-symmetric bending mode $(9.12 \mathrm{~Hz})$, two different numerical simulations were performed. The first consisted of modifying the mechanical characteristics of the structure, in order to increase the natural frequency of the first mode of vibration to the range of the first natural frequency of those cables. The second consisted of the application of a new artificially generated input signal, based on an almost rectangular power spectrum defined in a narrow frequency band that contains both the frequency of the third global mode of vibration (1st vertical antisymmetric) and the first natural frequency of some cables.

With these tests, the authors intended to analyze: a) the dynamic behaviour of a cablestayed bridge in a situation where the fundamental natural frequency is in the vicinity of the 1 st natural frequency of some stay cables; b) the effect of a narrow band excitation in a frequency range that contains both the first natural frequency of some cables and a global natural frequency of the bridge.

\subsection{Effect of cable-deck/towers resonance at the fundamental mode of vibration}

The numerical models of the Jindo bridge physical model were modified, by increasing the Young's modulus of the materials that constitute the deck/towers and stay cables, by factors of 2.8 and 2, respectively. This lead to an increase of the frequency of the first vertical bending mode from $6.21 \mathrm{~Hz}$ to $9.01 \mathrm{~Hz}$, while the fundamental frequencies of the cables increased from $6.81 \mathrm{~Hz}-18.92 \mathrm{~Hz}$ to $7.73 \mathrm{~Hz}-23.69 \mathrm{~Hz}$.

The analysis of mode shape configurations for the new OECS and MECS models shows that groups of symmetric mode shapes alternate with groups of anti-symmetric modes (note that this designation is applied to describe only the configuration of the deck and towers). It is also evident, according to Table III, which presents the mimimum ratio between the maximum normalised modal displacement components (along the three orthogonal directions $\mathrm{x}, \mathrm{y}$ and $\mathrm{z}$ ) of the group of cables and of the deck/towers, that the MECS analysis produced many new modes 
of vibration associated with the same first symmetric vertical configuration. These modes involve significant interference with cables.

Table III. Calculated natural frequencies of modified models

\begin{tabular}{|c|c|c|c|c|}
\hline Mode number & $\begin{array}{c}\text { MECS } \\
\text { natural fre- } \\
\text { quency }(\mathrm{Hz})\end{array}$ & $\begin{array}{c}\text { Associated } \\
\text { OECS } \\
\text { frequency }(\mathrm{Hz})\end{array}$ & $\begin{array}{c}\text { Min.ratio of } \\
\text { cable/beam max. } \\
\text { displ . }\end{array}$ & Type of mode \\
\hline$\overline{1}$ & 6.62 & 6.72 & 2.2 & $1^{\text {st }}$ transv. SYM \\
\hline 3 & 7.78 & $9.01 / 6.72$ & 4.9 & $1^{\text {st }}$ vert. SYM $+1^{\text {st }}$ transv. ASM \\
\hline 4 & 7.78 & $9.01 / 11.71$ & 4.3 & $1^{\text {st }}$ vert. SYM $+1^{\text {st }}$ transv. ASM \\
\hline 8 & 8.02 & 11.71 & 15.6 & $1^{\text {st }}$ transv. ASM \\
\hline 9 & 8.03 & 6.72 & 13.7 & $1^{\text {st }}$ transv. SYM \\
\hline 11 & 8.46 & 9.01 & 6.0 & $1^{\text {st }}$ vert. SYM \\
\hline 12 & 8.46 & 9.01 & 7.5 & $1^{\text {st }}$ vert. SYM \\
\hline 13 & 8.46 & 9.01 & 6.2 & $1^{\text {st }}$ vert. SYM \\
\hline 14 & 8.46 & 9.01 & 6.1 & $1^{\text {st }}$ vert. SYM \\
\hline 15 & 8.46 & 9.01 & 6.0 & $1^{\text {st }}$ vert. SYM \\
\hline 16 & 8.46 & 9.01 & 6.2 & $1^{\text {st }}$ vert. SYM \\
\hline 17 & 8.47 & 9.01 & 6.1 & $1^{\text {st }}$ vert. SYM \\
\hline 21 & 8.72 & 9.01 & 16.2 & $1^{\text {st }}$ vert. SYM \\
\hline 25 & 8.83 & 6.72 & 17.0 & $1^{\text {st }}$ transv. SYM \\
\hline 27 & 8.98 & 9.01 & 12.0 & $1^{\text {st }}$ vert. SYM \\
\hline 28 & 8.98 & 9.01 & 11.9 & $1^{\text {st }}$ vert. SYM \\
\hline 29 & 8.98 & 9.01 & 11.7 & $1^{\text {st }}$ vert. SYM \\
\hline 44 & 11.2 & $9.01 / 6.72$ & 13.0 & $1^{\text {st }}$ vert. SYM $+1^{\text {st }}$ transv. SYM \\
\hline 45 & 11.2 & $9.01 / 6.72$ & 10.5 & $1^{\text {st }}$ vert. SYM $+1^{\text {st }}$ transv.SYM \\
\hline 53 & 12.0 & 13.72 & 12.5 & $1^{\text {st }}$ vert. ASM \\
\hline 54 & 12.0 & 13.72 & 12.0 & $1^{\text {st }}$ vert. ASM \\
\hline 55 & 12.0 & 13.72 & 14.9 & $1^{\text {st }}$ vert. ASM \\
\hline 56 & 12.1 & 13.72 & 17.7 & $1^{\text {st }}$ vert. ASM \\
\hline 57 & 12.2 & & 5.9 & tranversal \\
\hline 59 & 13.6 & 13.72 & 11.8 & $1^{\text {st }}$ vert. ASM \\
\hline 61 & 13.6 & 13.72 & 13.9 & $1^{\text {st }}$ vert. ASM \\
\hline 63 & 13.6 & 13.72 & 14.0 & $1^{\text {st }}$ vert. ASM \\
\hline 67 & 14.1 & 13.72 & 12.0 & $1^{\text {st }}$ vert. ASM \\
\hline 77 & 15.8 & 13.72 & 10.2 & $1^{\text {st }}$ vert. ASM \\
\hline 79 & 15.8 & $13.72 / 6.72$ & 10.1 & $1^{\text {st }}$ vert. ASM $+1^{\text {st }}$ transv. SYM \\
\hline 85 & 16.4 & $13.72 / 11.71$ & 21.2 & $1^{\text {st }}$ vert. ASM $+1^{\text {st }}$ transv. ASM \\
\hline 87 & 16.4 & $13.72 / 11.71$ & 25.0 & $1^{\text {st }}$ vert. ASM $+1^{\text {st }}$ transv. ASM \\
\hline
\end{tabular}

The participation factors along the longitudinal $(\mathrm{X})$ and vertical $(\mathrm{Z})$ directions, presented in Figure 13, show the contribution of a significant number of modes (from the MECS analysis) to the response.
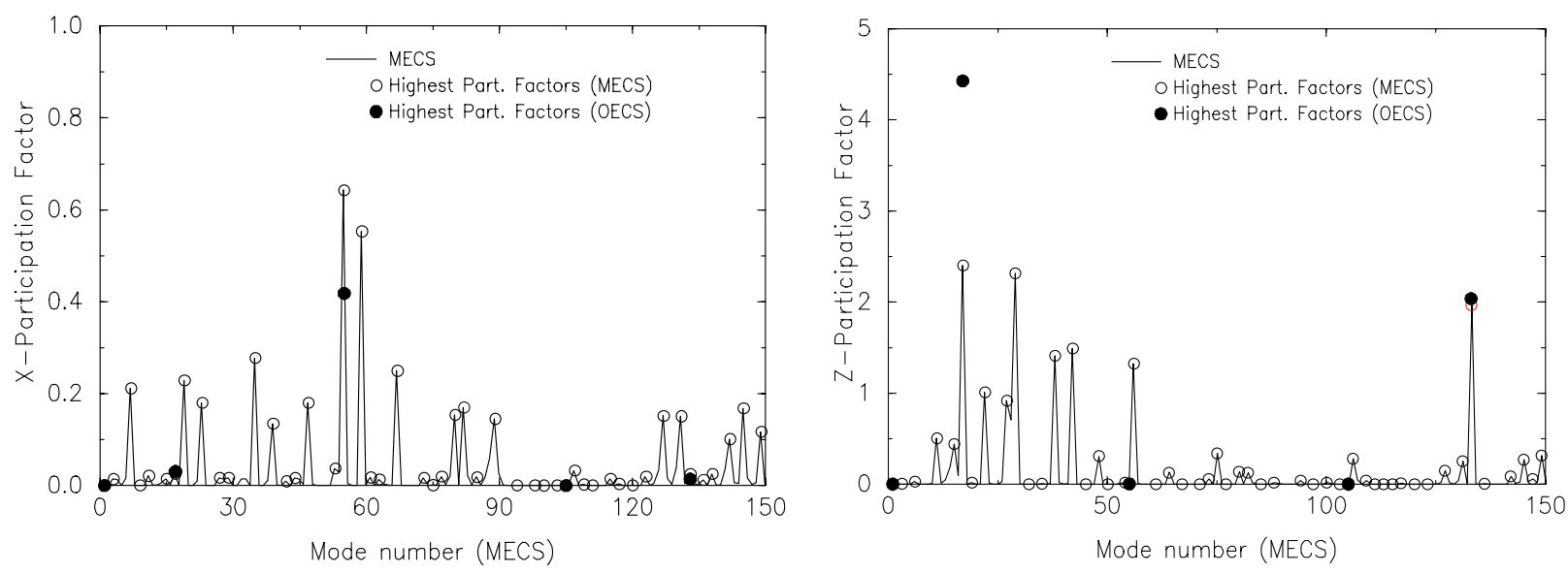

Figure 13. Participation factors associated with models OECS and MECS 
The calculation of the response of the OECS and MECS models of the new structure to the combination $\mathrm{XZ}(10 \% \mathrm{~g}(\mathrm{X}), 6 \% \mathrm{~g}(\mathrm{Z}))$ of accelerograms from record RRS1 above described, was based on a geometric non-linear formulation, using the direct integration method of Newmark and the same mass-proportional damping matrix $(\mathrm{f}=6.20 \mathrm{~Hz}, \xi=1.0 \%)$. Figures 14 and 15 show the peak dynamic response along the deck and one of the towers, and along the cables, respectively, expressed in terms of displacements, accelerations and bending moments.
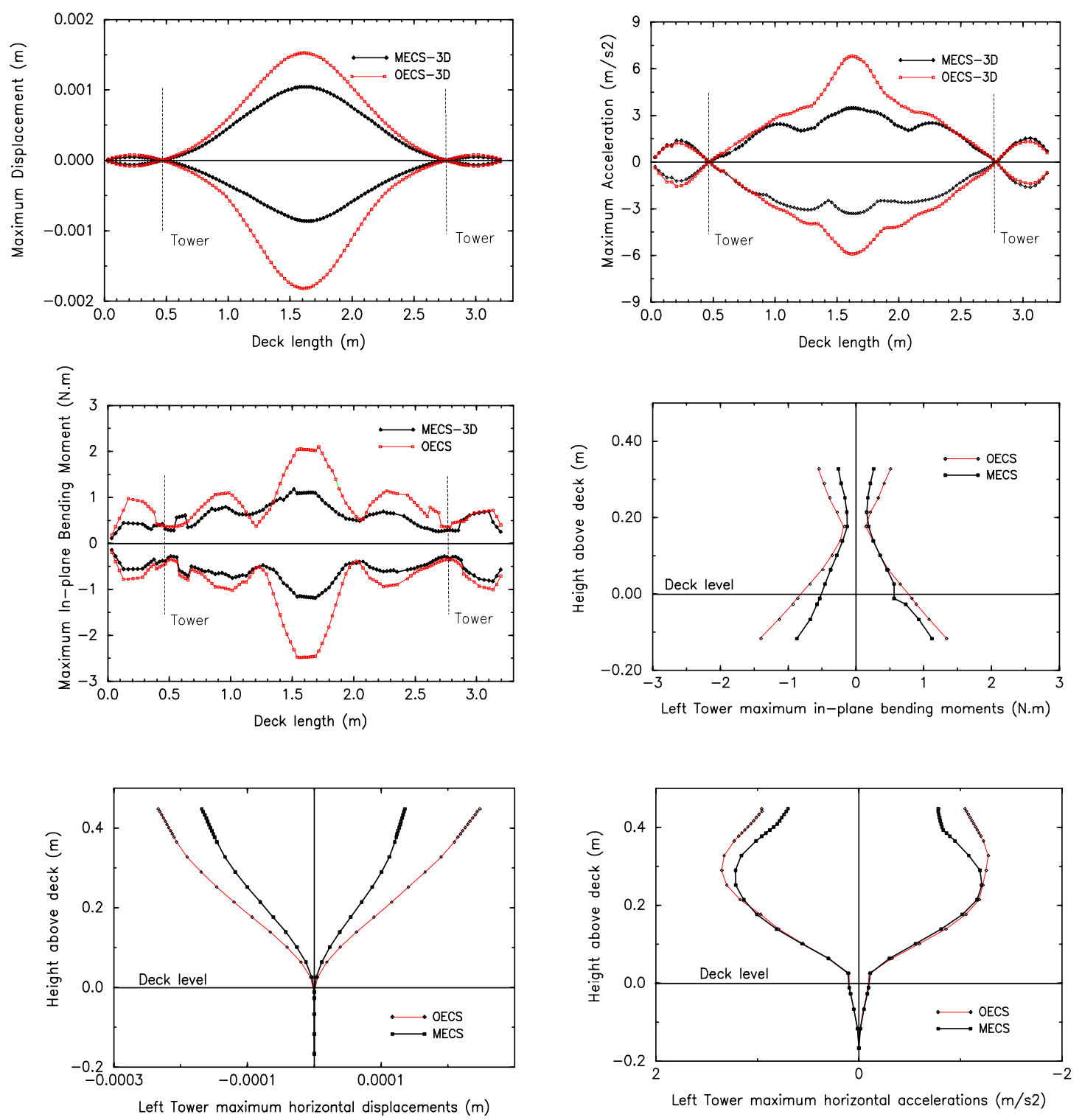

Figure 14. Peak response along the deck and left tower: displacements, accelerations and bending moments 

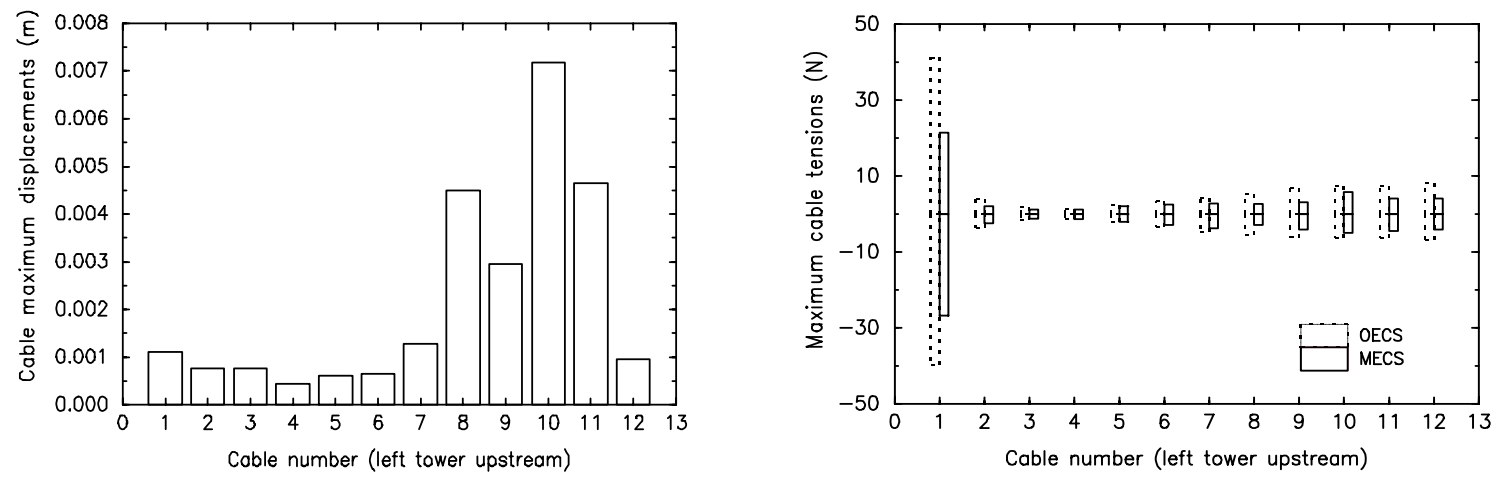

Figure15. Peak response along the cables: displacements and tensions

Figure 16 represents the time history of the bending moment response at node D4 and the corresponding Fourier spectrum. The relative difference between the peak response calculated at some significant locations, based on the OECS and MECS analyses, is presented in Table IV.
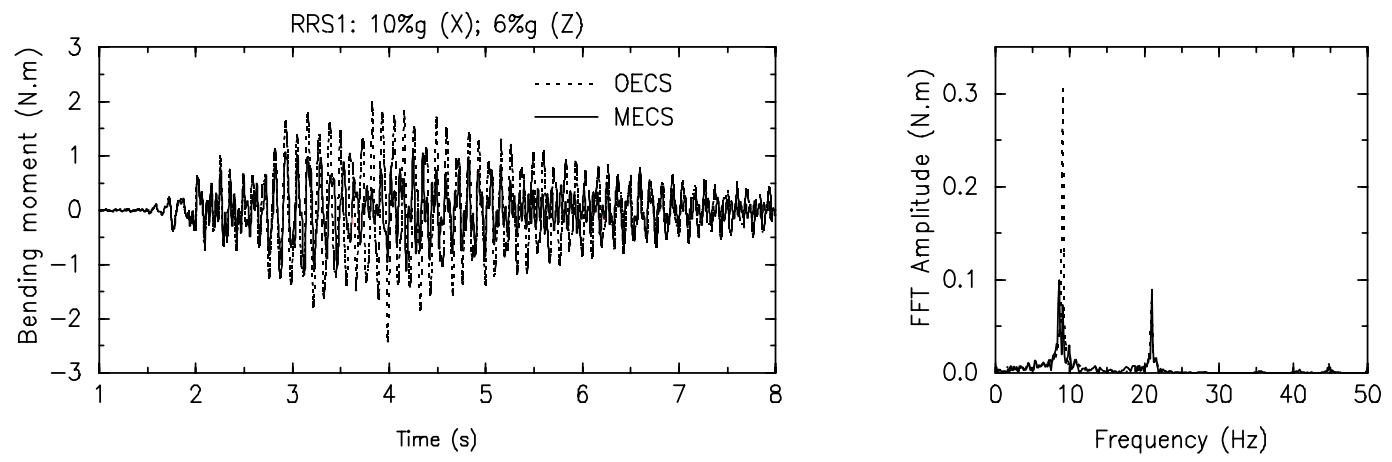

Figure 16. Bending moment at node D4, MECS vs OECS analysis.

Time history and Fourier spectrum

Table IV. Change of peak response, MECS vs OECS analysis

\begin{tabular}{lcccc}
\hline & \multicolumn{4}{c}{ Change of peak response $($ MECS / OECS ) } \\
\cline { 2 - 5 } Type of response & Deck & Node no. & Towers & Node no. \\
\hline \multirow{2}{*}{ Displacement } & $48.2 \%$ & $\mathrm{D} 4-\mathrm{Z}$ & $54.8 \%$ & LT1-X \\
Acceleration & $51.9 \%$ & $\mathrm{D} 4-\mathrm{Z}$ & $72.8 \%$ & LT1-X \\
Bending moment & $54.5 \%$ & $\mathrm{D} 4$ & $67.4 \%$ & LT2 \\
\hline
\end{tabular}


The analysis of this table and of Figures 14 to 16 illustrates that, except for small extensions along the deck, the response obtained on the basis of the MECS analysis is much lower than the corresponding response obtained from the OECS analysis. This effect constitutes the so called "system damping". The damping of the response is due mostly to the contribution of the several new modes of vibration associated with the 1 st symmetric vertical configuration. These modes, occurring at close frequencies $(7.78 \mathrm{~Hz}, 8.46 \mathrm{~Hz}, 8.47 \mathrm{~Hz}, 8.72 \mathrm{~Hz}, 8.98 \mathrm{~Hz})$ involve exclusively the movement of cables that have similar natural frequencies (e.g. mode 17, freq. $=8.47 \mathrm{~Hz}$, involves vibration of cables $8,9,10$ and 11 , whose first natural frequencies are $9.39 \mathrm{~Hz}, 8.94 \mathrm{~Hz}, 8.29 \mathrm{~Hz}$ and $7.75 \mathrm{~Hz}$, respectively).

\subsection{Effect of severe cable excitation}

Using again the 3-D OECS and MECS numerical models defined initially, the response of the physical model of Jindo bridge to a new input signal was calculated and analysed. The new accelerogram was generated artificially, based on a narrow-band target power spectrum, defined in the range $8.5-12 \mathrm{~Hz}$, that includes the frequency of the second vertical mode of vibration (according to the OECS analysis) and the first natural frequency of a few stay cables that participate in the modes of vibration obtained from the MECS analysis. Figure 17 presents the generated time history and the corresponding Fourier spectrum.
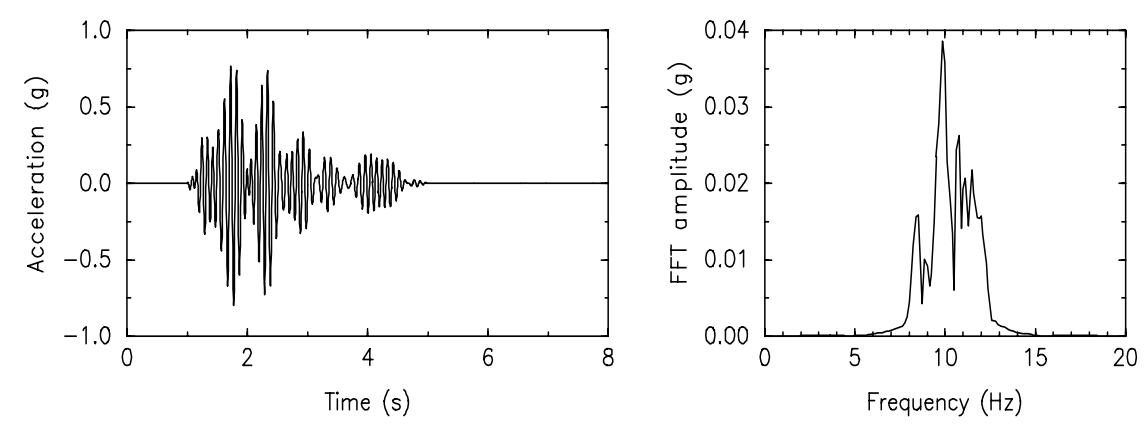

Figure 17. Artificial record of ground motion. Acceleration time history and Fourier spectrum 
Considering a combination of two time histories from the generated record with $60 \% \mathrm{~g}$ and 30\%g peak values along $\mathrm{X}$ and $\mathrm{Z}$ directions, respectively, and imposing a damping factor $\xi_{1}=1.0 \%$ for the first mode of vibration $\left(f_{1}=6.20 \mathrm{~Hz}\right)$ in order to generate a mass-proportional damping matrix, the system response has been calculated for the OECS and MECS models (using a geometric non-linear formulation and the direct integration method of Newmark). Figures 18 to 20 summarise the global response of the bridge in terms of the following extreme values: displacements, accelerations, bending moments and axial forces. Figures 21 to 23 represent the time and frequency response in terms of displacement, acceleration and bending moment at nodes D4-Z, D5-Z and LT4, respectively. Table V summarises the negative and positive peak values obtained on some of the most representative nodes of the structure.
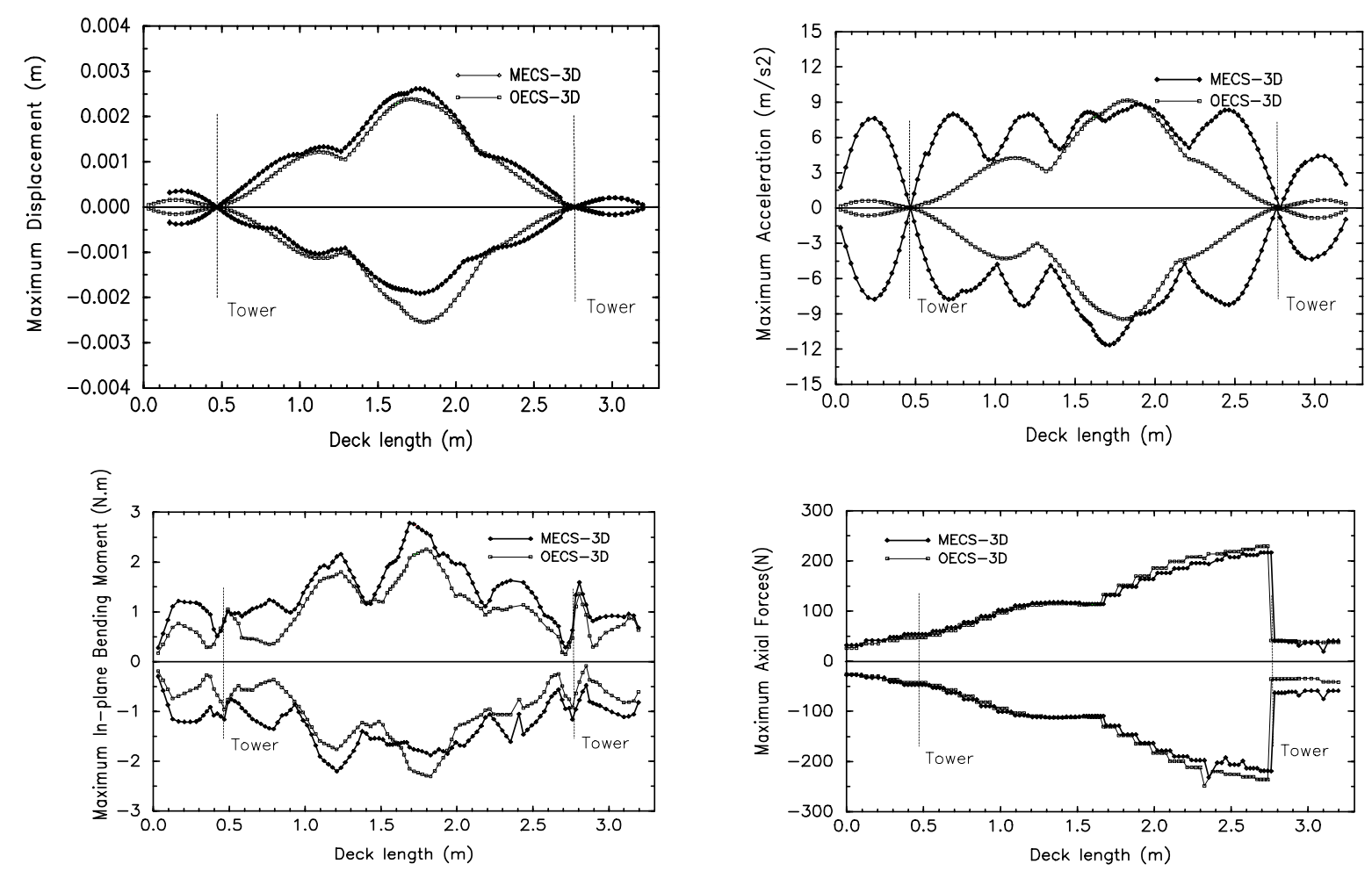

Figure 18. Peak responses along the deck: OECS vs MECS displacements, accelerations, bending moments and axial forces 

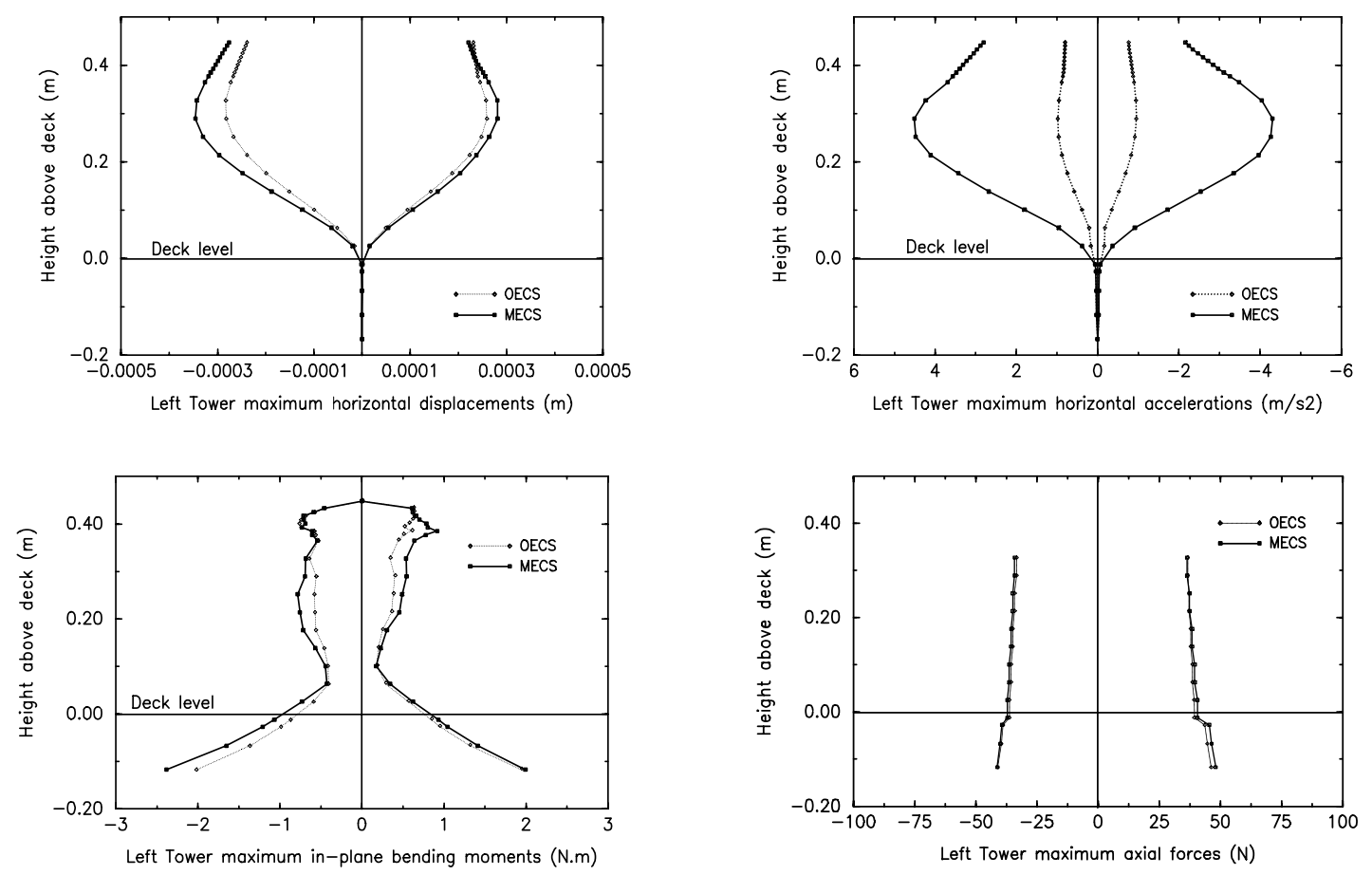

Figure 19. Peak responses along the left tower: OECS vs MECS displacements, accelerations, bending moments and axial forces
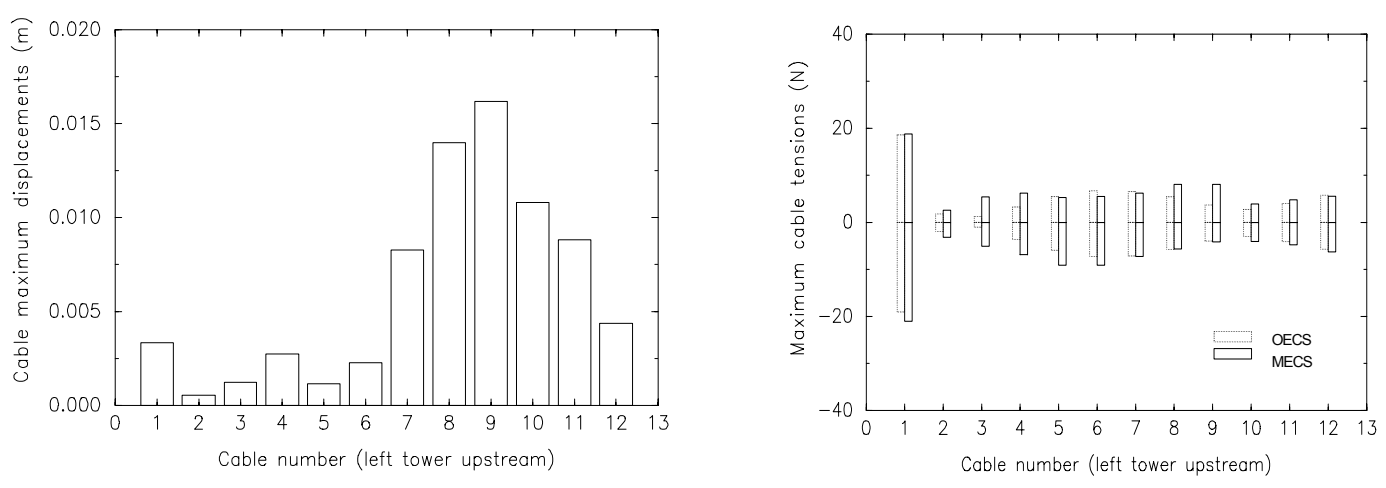

Figure 20. Peak responses along the cables: OECS vs MECS displacements at midpoint and tensions
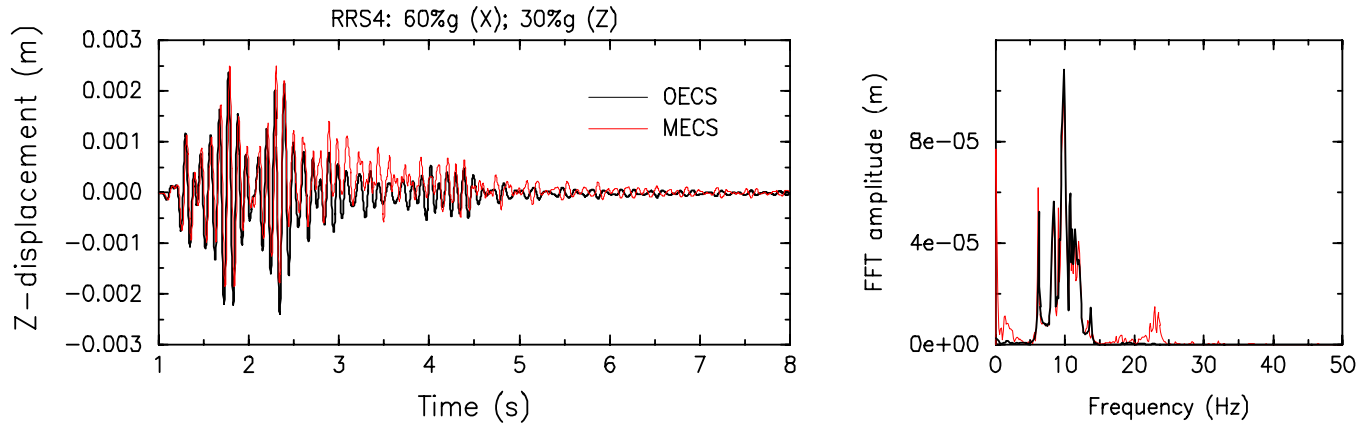

Figure 21. Input RRS4 - Displacement calculated at node D4-Z and corresponding Fourier spectrum, OECS vs MECS 

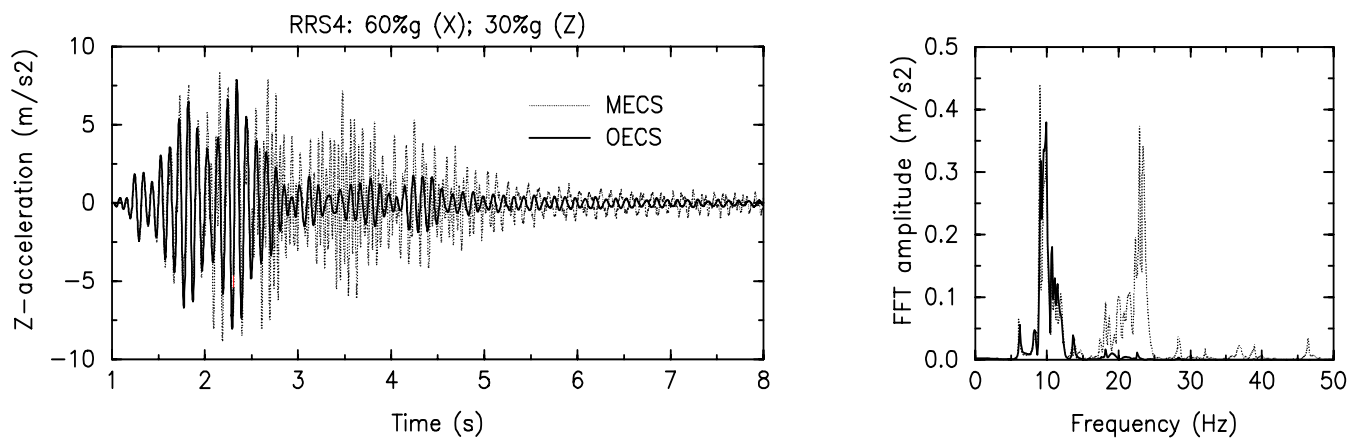

Figure 22. Input RRS4 - Acceleration calculated at node D5-Z and corresponding Fourier spectrum, OECS vs MECS
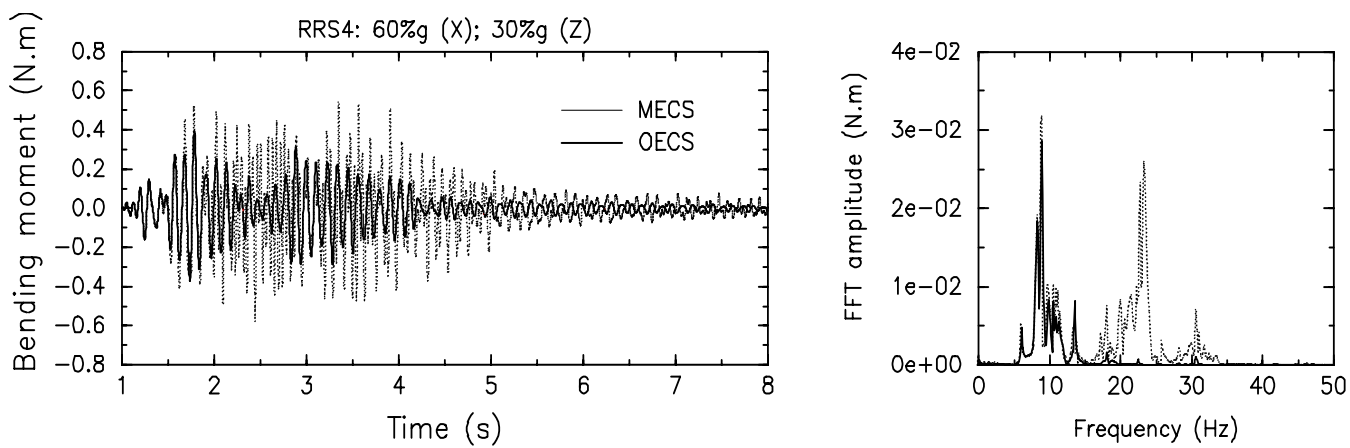

Figure 23. Input RRS4 - Bending moment calculated at node LT4 and corresponding Fourier spectrum in the range 2-8s, OECS vs MECS

Table V. Peak response for input RRS4 - 60\%g (X), 30\%g (Z)

\begin{tabular}{cccc}
\hline Response & OECS & MECS & $\begin{array}{c}\text { Change } \\
\text { (MECS / OECS) } \\
\%\end{array}$ \\
\hline D4-Z, accel. (m/s2) & $-8.97 / 8.29$ & $-11.6 / 7.41$ & $129.3 / 89.4$ \\
D5-Z, accel. (m/s2) & $-8.00 / 8.24$ & $-8.81 / 8.52$ & $110.1 / 103.4$ \\
LT1-X, accel. (m/s2) & $-0.80 / 0.76$ & $-2.81 / 2.16$ & $351.2 / 284.2$ \\
D4-Z, displ. (m) & $-0.00237 / 0.00238$ & $-0.00184 / 0.00251$ & $77.6 / 105.5$ \\
D5-Z, displ. (m) & $-0.00219 / 0.00199$ & $-0.00154 / 0.00212$ & $70.3 / 106.5$ \\
LT1-X, displ. (m) & $-0.000239 / 0.000231$ & $-0.000276 / 0.000221$ & $115.5 / 95.7$ \\
D4, bend. mom. (N.m) & $-2.15 / 2.08$ & $-2.72 / 2.78$ & $126.5 / 133.7$ \\
D5, bend. mom. (N.m) & $-1.56 / 1.47$ & $-1.73 / 2.00$ & $110.9 / 136.0$ \\
LT3, bend. mom. (N.m) & $-0.591 / 0.559$ & $-0.733 / 0.622$ & $124.0 / 112.7$ \\
D5, axial force (N) & $-165.1 / 169.9$ & $-163.1 / 163.6$ & $98.8 / 96.3$ \\
LT3, axial force (N) & $-36.2 / 39.4$ & $-37.1 / 40.6$ & $102.5 / 103.0$ \\
Cable 1, left, tension (N) & $-19.1 / 18.6$ & $-21.0 / 18.8$ & $109.9 / 101.1$ \\
Cable 8, left, tension (N) & $-5.8 / 5.5$ & $-5.7 / 8.1$ & $98.3 / 122.7$ \\
Cable 9, left, tension (N) & $-3.9 / 3.7$ & $-4.2 / 8.1$ & $107.7 / 218.9$ \\
\hline
\end{tabular}

Inspection of this table and these figures shows that, except for the axial force, the inclusion of the local cable behaviour in the analysis (MECS) leads to a significant increase of the peak response. This occurs in consequence of a high spectral content of the response at high frequencies (Figures 21 to 23), which develops only about 2s after the excitation has been applied. 
It was also possible to observe that, during the excitation period, cables 8 and 9 experienced relatively high levels of vibration. Figure 24, representing the ratio between the maximum amplitude of displacement at the cable mid-point and the corresponding length for the cables attached to the left tower, illustrates the relative importance of cable motion for the three analyses performed. The significant cable movement associated with the narrow band excitation (input RRS4) may be responsible for a marked non-linear character of the oscillations, evidenced by the translation upwards of the curves that represent peak displacements along the deck, and by a certain loss of regularity of the curves that represent the peak response along the deck (Figure 18).

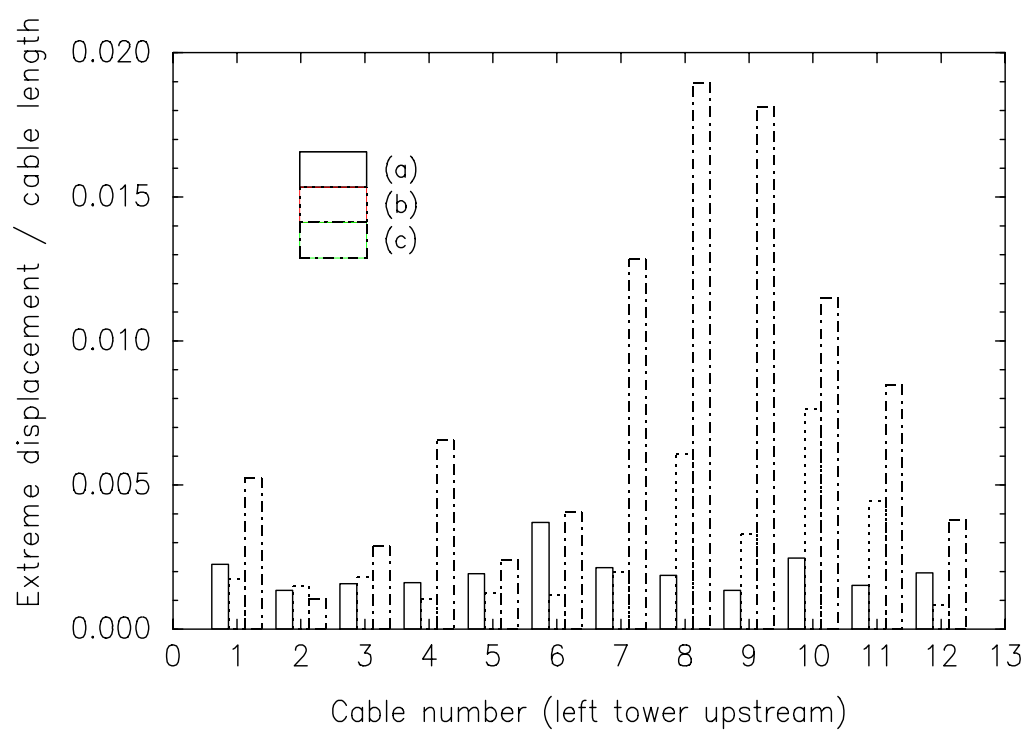

Figure 24. Cable motion associated to (a)Jindo model, input RRS1; (b)Jindo modified model, input RRS1; (c) Jindo model, input RRS4

\section{CONCLUSIONS}

The investigation involved the following topics:

1. Shaking table tests on the physical model of Jindo bridge, using artificial accelerograms (records RRS1);

2. Numerical analysis of the seismic response of the Jindo bridge physical model to earthquake excitation characterised by the records RRS1, using both the OECS and MECS (RRS1 analysis); 
3. Numerical analysis of the seismic response of the physical model under the same input excitation, simulating a modification of the structural properties, in order to induce a global cable-deck-towers resonance (RRS1M analysis);

4. Numerical analysis of the seismic response of the physical model to a severe narrow-band cable excitation, using OECS and MECS models (RRS4 analysis).

From the set of results presented, it is possible to draw in particular the following conclusions:

- The results from tests performed on the shaking table for different artificially generated input actions present a reasonable correlation with the numerical response calculated on the basis of the OECS and MECS analysis. The main discrepancies that were found to correspond to a slight change of frequency and to a complex variation of the damping with the amplitude and frequency of the measured response. These aspects reflect some imprecision related with the difficulty of accurately modelling the real damping characteristics and some local details of the structure;

- Concerning the RRS1 analysis, it was observed that, due to the relatively high frequency content of the input excitation in the range of the natural frequency of the first vertical bending mode, the response was strongly dominated by this mode of vibration. For the type of excitation employed, involving a relatively low excitation of the stay cables, it was possible to observe that these cables didn't provide significant damping of the structural response in terms of maximum peak values. However, this damping developed some time after the excitation started, leading then to a considerable decrease of the response. It is noteworthy that the increase of some peak response values in the MECS analysis reflects the non-linear character induced by the vibration of the cables during an initial period of oscillation, before "system damping" effects occur;

- The modification of the structural properties considered in the RRS1M analysis led to a magnification of this effect of "system damping". In fact, the increase of the frequency of the fundamental vertical bending mode to the range of the first natural frequencies of the cables, resulted, for the MECS analysis, in the appearance of a very significant number of modes of vibration at very close frequencies, having the same first symmetric configuration of the deck 
and towers, and involving different movements of the cables. The contribution of these modes tends to cancel and, as a result, the response decreases significantly with regard to the OECS analysis;

- Both RRS1 and RRS1M analyses involved a relatively small level of cable vibration and a small degree of non-linearity. The RRS4 analysis was intended to evaluate the effect of strong cable motion in the response. So, the excitation was generated artificially, defined in a frequency range that included only the third global mode of vibration (according to the OECS model) and the 1st frequency of a few stay cables. It was possible to observe that some of the cables experienced an important level of vibration. This caused significant non-linearity, and a significant increase of the upwards vertical deck displacements. Also, it was observed that high frequency vibration was induced, causing very high increase of acceleration at the deck and towers. The fact that high frequency components only develop some time after the start of the excitation indicates that the peak response increase is not so significant as the increase of the global response.

In view of these results, the authors believe that, for relatively small levels of vibration, the cables may act favourably in the reduction of the global response of the cable-stayed bridge. This damping effect is more important if the natural frequencies of the fundamental modes of vibration lie in the range of the first natural frequency of the cables. But for high levels of cable vibration, like those caused by an excitation defined in a narrow frequency band that contains the first natural frequency of the cables, significant non-linearity may cause high frequency vibration to occur. This vibration is associated with higher cable modes and can induce contributions of higher order global modes of the structure, resulting in an unfavourable behaviour of the bridge.

\section{ACKNOWLEDGEMENTS}

The present investigation work was carried out at the EERC at the University of Bristol and funded from the Human Capital and Mobility Programme of the European Union, under the ECOEST Programme (European Consortium of Earthquake Shaking Tables) and in conjunction 
with research contracts from the UK Engineering and Physical Sciences Research Council and from the Portuguese Foundation for Science and Technology (FCT). The writers wish to acknowledge the help of Prof. R. Severn, as well as the advice of Dr. A. Blakeborough and the technical support of Mr. D. Ward.

\section{REFERENCES}

1. Leonhardt, F. and Zellner, W., "Cable-stayed bridges", IABSE surveys, S-13/80, (1980).

2. Maeda, Y., Maeda, K. and Fujiwara, K., "System damping effect and its application to design of cable-stayed bridge", Technology reports of the Osaka University, 33, No. 1699, 125-135 (1983).

3. Ernst, H., "The modulus of elasticity of cable taking into account of catenary action", Der bauingenieur, 40, No. 2, 52-55 (1965).

4. Fujino, Y., Warnitchai, P. And Pacheco, B., "An experimental and analytical study of autoparametric resonance in a 3DOF model of cable-stayed beam", Nonlinear dynamics, 4, 111138 (1993).

5. Causevic, M. S. and Sreckovic, G., "Modelling of cable-stayed bridge cables: effects on bridge vibrations", Proc. of the int. conf. on cable-stayed bridges, Bangkok, 1987, pp. $407-$ 420.

6. Kovacs, I., "Zur frage der seilschwingungen und der seildampfung", Die bautechnik, October, 325-332 (1982).

7. Abdel-Ghaffar, A. M. and Khalifa, M. A. - "Importance of cable vibration in dynamics of cable-stayed bridges", Journal of engineering mechanics, ASCE, 117, No. 11, 2571-2589, (1990).

8. Tuladhar, R. And Brotton, D., "A computer program for nonlinear dynamic analysis of cablestayed bridges under seismic loading", Proc. of the int. conf. on cable-stayed bridges, Bangkok, 1987, pp.315-326.

9. Baron, F. And Lien, S-Y., "Analytical studies of a cable-stayed girder bridge", Computers \& structures, 3, 443-465, (1973). 
10. Yiu, P. and Brotton, D., "Mathematical modelling of cable-stayed bridges for computer analysis", Proc. of the int. conf. on cable-stayed bridges, Bangkok, 1987, pp. 249-260.

11. Tuladhar, R., Dilger, W. And Elbadry, M., "Influence of cable vibration on seismic response of cable stayed bridges", Canadian journal of civil engineering, 22, 1001-1020, (1995).

12. Garevski, M. A. - "Dynamic analysis of cable-stayed bridges by means of analytical and physical modelling", Ph.D. Thesis, Department of Civil Engineering, University of Bristol, U.K. 1990.

13. Caetano, E., Cunha, A. and Taylor, C., "Investigation of dynamic cable-deck interaction in a cable-stayed bridge physical model. Part I: Modal response", Earthquake engineering and structural dynamics, submitted for publication (1999).

14. SOLVIA 95.0 Finite element system, SOLVIA Engineering AB, Sweden, 1995. 